\title{
Earthquake Probabilities
}

\section{in the San Francisco Bay Region:}

\section{0 to 2030-A Summary}

\section{of Findings}

By Working Group on California Earthquake Probabilities

Open-File Report 99-517

1999

This report is preliminary and has not been reviewed for conformity with U.S. Geological Survey editorial standards or with the North American Stratigraphic Code. Any use of trade, firm, or product names is for descriptive purposes only and does not imply endorsement by the U.S. Government.

\section{U.S. DEPARTMENT OF THE INTERIOR}

U.S. GEOLOGICAL SURVEY 


\section{PREFACE}

This report summarizes the results of a new analysis of the probability of significant earthquakes in the San Francisco Bay region for the coming three decades. The principal results of this study, which was led by the U.S. Geological Survey (USGS), are being released on October 14, 1999, by three means: (1) in a presentation by the Working Group Chair, Dr. David Schwartz, to local and national government figures and earthquake response officials at a General Assembly of the Association of Bay Area Governments, commemorating the tenth anniversary of the 1989 Loma Prieta earthquake; (2) in USGS Fact Sheet 152-99, "Major Quake Likely to Strike Between 2000 and 2030," written for a general audience; and (3) in the following document, written for a more technically inclined audience that may include scientists, engineers, hazard experts, and science writers. This document begins with a Summary, followed by a Preliminary Technical Report for those interested in details of the methods employed by the Working Group.

A full and final report is to appear as USGS Circular 1189, "Earthquake Probabilities in the San Francisco Bay Region: 2000 to 2030" at a later date. 


\section{CONTENTS}

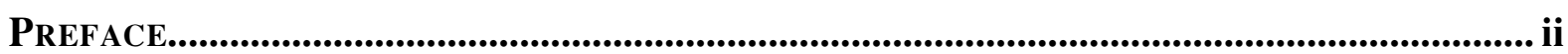

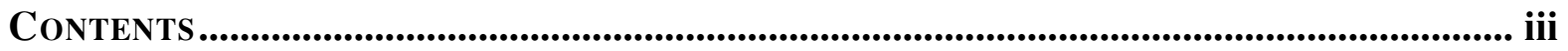

List of Figures......................................................................................................... iv

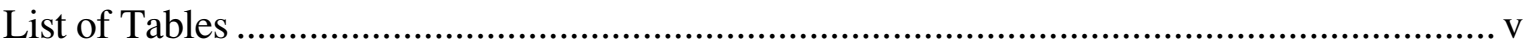

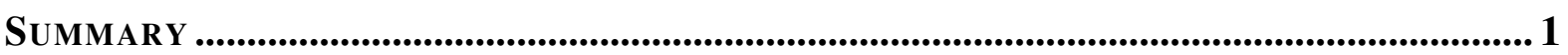

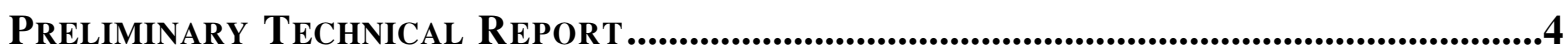

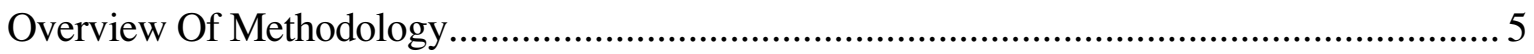

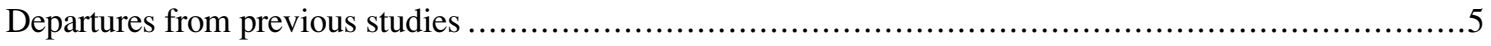

Part 1 Of Method: Building The Regional Earthquake Model ............................................... 8

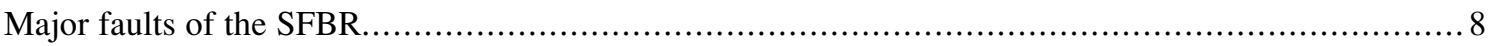

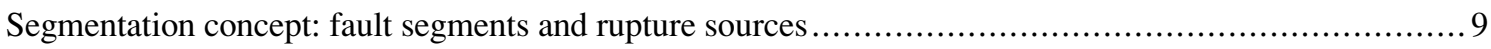

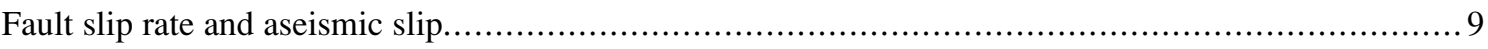

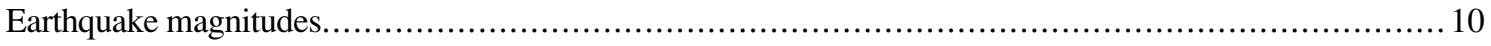

Building moment-balanced models for each fault and for the region............................................. 10

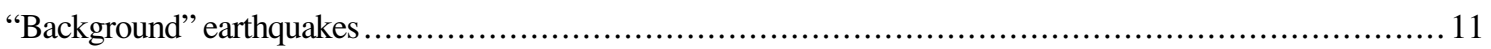

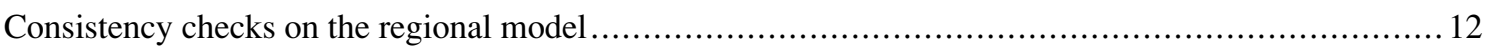

Mean rupture rates on fault segments................................................................................... 13

Part 2 of Method: Calculating 30-year Earthquake Probabilities .......................................... 14

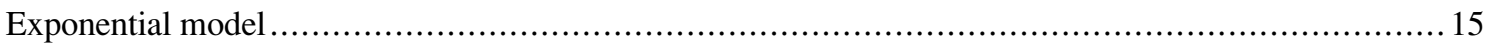

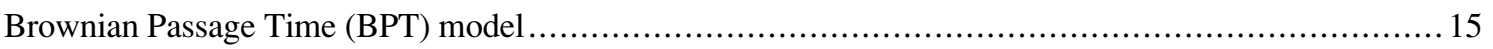

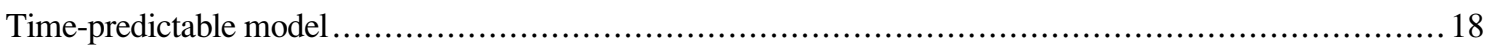

Probability Calculation Results .................................................................................... 18

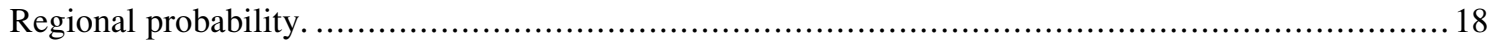

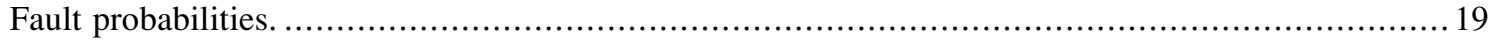

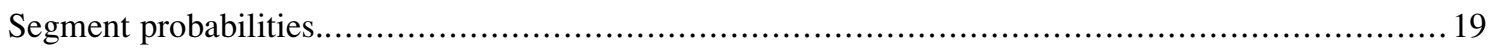

Probability of smaller earthquakes in the San Francisco Bay Region...............................................2 20 


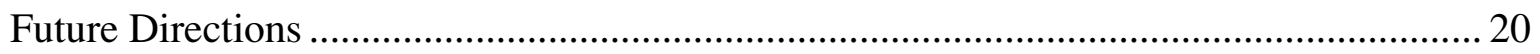

ApPendix A: Working Group Participants................................................................... 21

APPENDIX B: GEOLOGIC AND GEODETIC INPUT DATA............................................................ 25

Appendix C: New Magnitude-Area Relations............................................................. 29

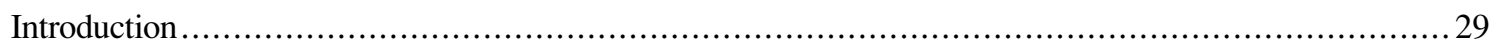

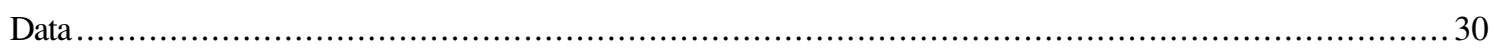

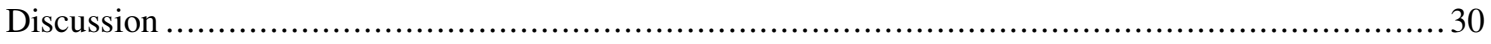

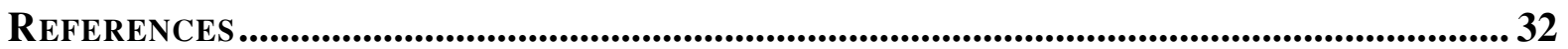

\section{LIST OF FIGURES}

1. San Francisco Bay region, with labels indicating the probabilities that its major faults will rupture in one or more M6.7 earthquakes before 2030.

2. Map of the SFBR showing the rectangular area considered by WG99.

3. Diagram of Hayward-Rodgers Creek fault segments and their possible combinations.

4. Frequency-magnitude relation predicted by the WG99 regional model, fit by a Gutenberg-Richter model.

5. Summary of regional rates of $M \geq 6.7$ earthquakes inferred from Gutenberg-Richter models.

6. Time sequence of large earthquakes in the SFBR since the early nineteenth century.

7. Probability density function for a time-dependent probability model.

C1. Magnitude versus area for major strike-slip faults, with the various fits of Wells and Coppersmith (1994) and Somerville et al. (1999).

C2. Magnitude versus area data, with three M-A relations used by WG99. 


\section{LIST OF TABLES}

1. Probability of at least one $\mathbf{M} \geq 6.7$ earthquake before 2030 .

2. Fault segment parameters.

3. Long-term magnitudes and rates on rupture sources.

4. Historical rates of earthquakes.

5. Segment rates for $\mathbf{M} \geq 6.7$ earthquakes.

6. Clock advance due to stress transfer from 1906 earthquake.

7. Probability of at least one $M \geq 6.7$ earthquake before 2030 by fault segment.

8. Probability of at least one $\mathrm{M} \geq 6.7$ earthquake before 2030 by fault and for region.

C1. Source parameters for large California strike-slip earthquakes. 


\section{SUMMARY}

The San Francisco Bay region sits astride a dangerous "earthquake machine," the tectonic boundary between the Pacific and North American Plates. The region has experienced major and destructive earthquakes in 1838, 1868, 1906, and 1989, and future large earthquakes are a certainty. The ability to prepare for large earthquakes is critical to saving lives and reducing damage to property and infrastructure. An increased understanding of the timing, size, location, and effects of these likely earthquakes is a necessary component in any effective program of preparedness.

This study reports on the probabilities of occurrence of major earthquakes in the San Francisco Bay region (SFBR) for the three decades 2000 to 2030. The SFBR extends from Healdsberg on the northwest to Salinas on the southeast (fig. 1) and encloses the entire metropolitan area, including its most rapidly expanding urban and suburban areas. In this study a "major" earthquake is defined as one with $\mathbf{M} \geq 6.7$ (where $\mathbf{M}$ is moment magnitude). As experience from the Northridge, California (M6.7, 1994) and Kobe, Japan (M6.9, 1995) earthquakes has shown us, earthquakes of this size can have a disastrous impact on the social and economic fabric of densely urbanized areas.

To reevaluate the probability of large earthquakes striking the SFBR, the U.S. Geological Survey solicited data, interpretations, and analyses from dozens of scientists representing a wide crosssection of the Earth-science community (Appendix A). The primary approach of this new Working Group (WG99) was to develop a comprehensive, regional model for the long-term occurrence of earthquakes, founded on geologic and geophysical observations and constrained by plate tectonics. The model considers a broad range of observations and their possible interpretations. Using this model, we estimate the rates of occurrence of earthquakes and 30-year earthquake probabilities. Our study considers a range of magnitudes for earthquakes on the major faults in the region-an innovation over previous studies of the SFBR that considered only a small number of potential earthquakes of fixed magnitude.

WG99 finds that:

1. There is a 0.70 probability $( \pm 0.1)$ of at least one magnitude 6.7 or greater earthquake before 2030 within the SFBR. Such earthquakes are most likely to occur on the seven fault systems characterized in the analysis (fig. 1). The probability value also includes a 0.09 chance of earthquakes on faults that were not characterized in this study.

2. The earthquake likelihood is distributed broadly across the SFBR (table 1). Previous studies characterized probabilities along the San Andreas and Hayward-Rodgers Creek Fault systems. Using new data and methods, WG99 included the San Gregorio Fault to the west and several faults to the east in its study. While the urban core remains at high risk, significant earthquake likelihood was identified in two of the most rapidly growing parts of the SFBR. Along the Interstate 680 corridor and in central and eastern Contra Costa and Alameda Counties, the Calaveras, Concord-Green Valley, Mount Diablo Thrust, and Greenville Faults present an aggregate probability of 0.30 for one or more $\mathbf{M} \geq 6.7$ quakes before 2030. Along the Pacific coast, in San 
Mateo, Santa Cruz and Monterey Counties, there is a similar aggregate probability (0.29) because of the close proximity of the San Andreas and San Gregorio Faults.

3. The Hayward-Rodgers Creek, San Andreas, and Calaveras Fault systems have the highest probabilities of generating a $\mathbf{M} \geq 6.7$ earthquake before 2030. These faults pose a direct threat to the cities of San Francisco, Oakland, and San Jose, which ring San Francisco Bay. The Hayward Fault is of particular concern because of the density of urban development along it and the major infrastructure lines (water, electricity, gas, transportation) that cross it.

4. The probability of at least one smaller (M6.0 to M6.7) earthquake in the SFBR before 2030 is estimated to be at least 0.80 . Earthquakes of this magnitude can produce significant damage over localized areas.

This report builds on previous analyses of earthquake likelihood, and it expands upon them to present a more comprehensive picture of earthquake occurrence throughout the region. In 1988, the first Working Group on California Earthquake Probabilities (Working Group on California Earthquake Probabilities, 1988, herein referred to as WG88), building on previous analyses by Lindh (1983) and Sykes and Nishenko (1984), concluded that for the SFBR the probability of one or more large (M about 7) earthquakes in the following 30 years was at least 0.5 . This conclusion was based on an analysis of information on the earthquake history and behavior of the San Andreas and Hayward Faults. After the1989 Loma Prieta earthquake, a second Working Group was convened (Working Group on California Earthquake Probabilities, 1990, herein referred to as WG90) and charged with reevaluating the region's earthquake probabilities in light of that event. By using new information and including the Rodgers Creek Fault, WG90 estimated the 30-year probability to be 0.67 . WG90 recognized that other faults in the region, including the Calaveras, San Gregorio, Concord-Green Valley, and Greenville Faults, also pose a serious danger. However, these faults were not included due to a lack of information.

The present findings of WG99 are based on geologic, geodetic, and seismologic information, much of it obtained since the 1989 Loma Prieta earthquake. Some of this information was reviewed and summarized in 1996 by the Working Group on Northern California Earthquake Potential (WGNCEP), whose report formed one basis for seismic shaking hazard maps of California (Petersen et al., 1996) and of the United States (Frankel et al., 1996). In addition to new data, new ideas of how faults work have emerged, and analysis methods have been refined to more formally incorporate uncertainty and alternative models into probabilistic estimates.

Among the recent advances in data and in the methodology employed by WG99 are:

1. Information on fault slip rates and earthquake recurrence (repeat) times now available for the northern Calaveras Fault, San Gregorio Fault, Concord-Green Valley Fault, and Greenville Fault, and on newly identified earthquake sources such as the Mt. Diablo blind thrust fault.

2. New information on fault segmentation from geological and geophysical observations. 
3. Reevaluation of the distribution of slip on the San Andreas Fault in the 1906 earthquake, coupled with new information on slip rates and earthquake recurrence in Marin County, on the San Francisco Peninsula, and in the Santa Cruz Mountains.

4. Improved knowledge of deformation in the region, in part derived from advances in Global Positioning System (GPS) measurements, and more precise locations and slip rates of reverse and blind thrust faults.

5. Applying the observed rate of tectonic plate motions as a constraint on regional earthquake rates.

6. Information on aseismic creep rates on the Hayward, Calaveras, and Concord-Green Valley Faults.

7. Effects of the 1906 earthquake in reducing earthquake activity for much of the 20th century, which can now be quantified and incorporated into time-dependent probability calculations.

8. Improved analytical methods for estimating the size and location of historical earthquakes, which have led to a new comprehensive catalog of $\mathbf{M} \geq 5.5$ earthquakes in the SFBR dating back to 1850 .

9. Comprehensive application of methods to incorporate uncertainty in both observational data and models of Earth processes. Expert opinion was solicited to evaluate data and alternative models.

There are important differences between the WG90 and WG99 studies. WG99 evaluated five additional faults, which might be expected to increase the estimated regional probability of major earthquakes. Any increase resulting from adding more faults was largely compensated for by two effects not included in the 1990 report: (1) reduction of earthquake activity throughout the region caused by the regional stress release in the 1906 earthquake, and (2) the inclusion of large, less frequent earthquakes in addition to smaller, more frequent ones.

As in any study based on limited data and still-maturing models, the results of the present assessment involve uncertainty. Rupture probabilities for individual fault segments are more uncertain than rupture probabilities for entire faults. The regional probability of 0.70 is more certain still, and has an estimated uncertainty of \pm 0.1 (one standard deviation). A full accounting of the estimated uncertainties will be given in the final report. As additional geologic data are obtained about the behavior of SFBR faults, uncertainties are expected to diminish.

It is anticipated that probability values will be revised in the future as understanding of the physics of the earthquake machine improves. However, it is encouraging that the probabilities calculated for the entire region and for large sub-areas within it are stable under the varying assumptions, interpretations, and methods used in the course of the WG99 study. This stability suggests that these results are robust, given our present state of knowledge. 


\section{PRELIMINARY TECHNICAL REPORT}

Earthquakes in the San Francisco Bay region (SFBR) have their origin in the release of strain energy by the sudden movement of a fault. Strain energy is constantly accumulating in the crustal rocks of the region because of the relative motion of the Pacific Plate relative to the North American Plate. Most of this relative motion of approximately $39 \mathrm{~mm} /$ year (1.5 inches/year) across the SFBR is accommodated by slip that occur during earthquakes episodically on relatively few faults and creates earthquakes.

This report is based on a regional model of strain accumulation and its release in earthquakes that is built from a combination of observational data on the faults, knowledge of past earthquakes, measured rates of strain accumulation, and expert opinion from the geologists and geophysicists with working knowledge of faults in the SFBR. Given our present state of knowledge, WG99 has restricted the model to earthquakes of moment magnitude $\mathbf{M} \geq 6$.7. Smaller, but still potentially damaging, earthquakes are included in the final probabilities using well-understood statistical models for regional seismic activity.

The following section presents an overview of the methodology used by WG99 and a description of the differences between this report and earlier working group studies. The regional model is then described in a step-by-step manner, emphasizing the most critical components of the model that define the earthquake generation process, and identifying where knowledge of them is uncertain. Because the regional model describes the long-term behavior of the fault system, averaged over thousands of years, it can be directly compared to historical rates of earthquake activity as a test of its validity.

The calculation of earthquake probabilities is outlined next. Three conceptually related models are used to compute the earthquake forecasts. One of these models assumes earthquake occurrence to be a homogeneous Poisson process in which the probability of earthquakes is uniform in time. The other two models employ the concept of the earthquake cycle, widely believed to govern earthquake occurrence. The tectonic process defining an earthquake cycle was first proposed by H.F. Reid (1910) in his study of the Great 1906 San Francisco Earthquake. In Reid's elastic rebound hypothesis, earthquakes are the result of slow accumulation of strain energy in the Earth. Before the next large earthquake can occur in the same location, strain energy must once again accumulate.

Our knowledge of both the physics of earthquakes and the nature of the faults in the SFBR is incomplete and uncertain, and the use of multiple models permits us to explore the bounds on the probability estimates. WG99 also factors in the influence that past earthquakes exert on the possibility of another event elsewhere in the SFBR.

The resulting earthquake probabilities for the 30-year period from 2000 to 2030 are presented as a regional summary for $\mathrm{M} \geq 6.7$ earthquakes. The probabilities are broken down by fault system, and finally by fault segment. The report concludes with some remarks about future changes and refinements to the probabilities that can be anticipated as a consequence of studies now in progress. 


\section{OVERVIEW OF METHODOLOGY}

WG99 introduces new geologic data and new methods of analysis for estimating earthquake probabilities in the SFBR. The new methods center around a regional model of the fault system based primarily on geologic data. WG99 characterizes each fault as a string of "fault segments," that are assumed to rupture either individually or in contiguous groups, thus producing on each fault a variety of sizes of earthquakes with varying frequencies. The regional model specifies the segmentation geometry and the combinations of segments most likely to fail in earthquakes, while constraining the aggregated rate of slip on the faults to balance, in the long term, the observed rate of motion between the Pacific and North American tectonic plates.

Computation of probabilities follows a sequence of steps, divided into two major parts: Part 1 consists of a series of steps resulting in construction of a regional model of long-term earthquake occurrence. The output of Part 1 characterizes the suite of magnitudes and recurrence times for earthquakes in the region and the long-term behavior of each fault segment defined in the region. Part 2 consists of additional steps that combine the long-term segment rupture rates from Part 1 with dates of previous earthquakes and a suite of probability models to calculate 30-year probabilities of earthquakes.

There are significant, defendable differences of opinion in the Earth-sciences community regarding the most appropriate models and best values of input parameters. Although much has been learned about the nature of faults and the earthquake-generation process in the region, many aspects of the physics of earthquakes are not yet determined. Consequently, multiple models can exist, each of which is consistent with the limited data available. In addition, there are uncertainties in measurements and observations. WG99 departs from previous SFBR probability reports by propagating uncertainty in models and data through the entire calculation sequence leading to 30-year probabilities. To accomplish this, WG99 applied and extended the "decision tree" approach used in WG90. In this approach, uncertainty arising from the data used is generally represented by a probability distribution about a point estimate, while uncertainties arising from choices among competing models (such as the segmentation model, area-magnitude relation, and probability model) are handled by branch points. Weights are assigned to the alternate branches that reflect expert opinion as it evolved in the study. The calculation procedure was constructed in this fashion to allow us to incorporate all forms of uncertainty.

\section{DEPARTURES FROM PREVIOUS STUDIES}

Although the new regional probability estimate of 0.70 is not significantly different from the 0.67 reported by WG90, critical differences distinguish the two studies. WG90 considered six separate segments of the San Andreas, Hayward, and Rodgers Creek Faults. Each fault segment was assumed to behave independently and produce earthquakes of one size. A probability was calculated using a timepredictable model. As this model was applied by WG90, the most likely time between the previous earthquake and the next on a segment was calculated as the slip in the last event divided by the longterm slip rate. Other faults, while recognized as being active, were not characterized by WG90 because information necessary to apply the time-predictable model was not available. 
WG99 expands on that approach in several distinct ways:

1. New data. WG99 utilizes new data and interpretations including those listed in the Summary section above.

2. Regional model of the earthquake-generation process. The goal of WG99 is the comprehensive assessment of large-earthquake probabilities in the SFBR. Like previous Working Groups, it subdivides the faults into a number of segments on the basis of geologic, geophysical and seismological information (fig. $\mathbf{2 A}, \boldsymbol{B}$ ). In addition, it allows for earthquakes that break multiple adjacent fault segments, and for floating earthquakes that represent ruptures on fault segments whose boundaries are unknown. Following on a concept introduced by the 1995 Southern California Earthquake Center (SCEC) Phase II report on southern California earthquake probabilities, WG99 also considers background earthquakes that might occur on faults either not characterized or not yet recognized. Seven faults are subdivided into nineteen segments; thirty-eight distinct rupture sources (segments and groups of contiguous segments) and 6 floating sources are characterized. Individual faults may generate earthquakes that involve the failure of one, two, three, or (in the case of the San Andreas Fault) four contiguous segments. Earthquake magnitudes are calculated from rupture source area, which varies greatly. Thus, the regional model allows for the occurrence of earthquakes distributed over a broad range of magnitudes.

3. Regional slip-rate constraint. The regional model is constrained by the requirment that the summed rates of fault slip (from earthquakes and creep) on transects across the region be consistent with the measured plate-motion rate of 36 to $43 \mathrm{~mm} /$ year. The model is further checked by comparing the predicted earthquake rates with historical seismicity and by comparing predicted fault-segment parameters with geologic observations. An intermediate output of the model is a suite of earthquake sources that characterize the long-term seismicity in the region, including mean values and distributions for the magnitude and annualized rate of occurrence of events on each fault. Also produced is the rate at which each fault segment is broken by earthquakes above a threshold magnitude of M6.7. This segment-specific information is used as input to the calculation of conditional 30-year probabilities.

4. Probability models. WG99 employs three distinct probability models to calculate 30 -year probabilities conditional upon an earthquake not having occurred by the beginning of the year 2000. As done by WG90, it uses the time-predictable model where the date and slip in the last large event are known; such information is known only for the San Andreas and southern Hayward Faults. To characterize the entire suite of faults, including those for which slip in the prior event—or even the date of that event - is unknown, WG99 uses renewal models. In the Brownian Passage Time (BPT) model, the effect of an earthquake is to reset the fault to a ground state from which it then evolves back towards a failure state through continued loading, tempered by interactions with nearby earthquakes. The ground state is independent of slip in the last event. Thus the strike-slip Calaveras, Concord-Green Valley, San Gregorio, and Greenville Faults and the blind Mt. Diablo Thrust Fault could be included in the calculations. Finally, 30-year Poisson (time-independent) probabilities for all fault segments and rupture sources were calculated. This calculation relies least on assumptions about the physics of the earthquake-generation process and assumes that 
earthquake occurrence is random in time, with no memory of previous events; the only input is the mean rate of occurrence of earthquakes above a threshold magnitude.

5. Faults loaded at the stressing rate. WG90 made the simplifying assumption that the loading of a fault segment occurs at the long-term geologic slip rate. In application of the time-predictable model WG99 assumes that fault loading is driven by deep shear under the suite of faults and, accordingly, calculates the loading rate for each fault segment using a three-dimensional elastic model.

6. Fault creep. Surface creep, rarely observed worldwide, is occurring on several strike-slip faults in the SFBR, including the Hayward, Calaveras, and Concord-Green Valley Faults. Although surface creep rates are well constrained, there are few estimates of the relative amount of moment released through creep and through earthquakes. Furthermore, little is known about how creep affects earthquake magnitudes and recurrence rates. WG99 commissioned expert groups to quantify the ratio of seismic to total slip, and their consensus values are used here with broad uncertainties ascribed. The estimated seismic slip factor is used to adjust the area of the fault segment contributing to earthquakes and thus tempers the earthquake magnitudes.

7. Fault interactions. WG90 estimated the change in loading stress on San Andreas Fault segments caused by slip in the 1989 Loma Prieta earthquake and calculated the resulting changes in recurrence times for these segments. Since then, the seismological community has extensively examined the ways faults interact by stress transfer, and such interactions are now generally accepted as an important component of earthquake physics. In WG99's analysis, interaction effects involving the 1906 and 1989 earthquakes are significant and are incorporated into the timedependent probability calculations.

8. Earthquake magnitudes. WG99 calculates an earthquake magnitude and its probable distribution for each rupture source as an explicit step in construction of the long-term regional model. The modeled rupture sources produce a suite of earthquakes over a broad range of magnitudes. The magnitude threshold $M \geq 6.7$ was chosen in consideration of two factors: (1) the regional geologic model is "complete" down to this magnitude level; i.e., the segmentation model for each major fault contains multiple sources capable of rupturing with such magnitudes; (2) M $\geq 6.7$ earthquakes are regional in the extent of their damage and pose a major threat to the SFBR. For example, the 1994 M6.7 Northridge, California, earthquake killed many people and caused \$20-40 billion damage in the Los Angeles area.

9. Smaller earthquakes. Although the scale of the regional fault model does not allow it to represent most earthquakes smaller than M6.7, earthquakes in the range $6.0 \leq \mathrm{M}<6.7$ are capable of causing significant damage in the SFBR, particularly if they occur in a heavily urbanized area. Therefore, WG99 estimated the regional probability for these earthquakes using a model based on historical earthquake activity.

10. Alternative models and uncertainties. Although much has been learned about the nature of faults and the earthquake generation process, many aspects of the physics of earthquakes are not yet understood. There are significant, defendable differences of opinion in the Earth sciences, and 
within WG99, regarding the appropriateness of various models of the earthquake process, and each competing model has uncertainty. There are also uncertainties in measurements and observations. WG90 introduced the use of logic trees to incorporate alternative segmentation and failure models for the Peninsula segment of the San Andreas Fault. WG99 has expanded on this practice, using weighted alternative values of inputs and models throughout the entire analysis.

An important consequence of this strategy is the ability to quantify the uncertainty in earthquake probability values. The final suite of probabilities represents a distribution of viable models, containing a range of potential behaviors of the regional earthquake machine, and preferences of theories, hypotheses, and observations contained in the analysis. As knowledge is improved of the physics of earthquakes and the behavior of SFBR faults, the range of defendable models will narrow and uncertainties will contract. Thus, it can be anticipated that the results of research now in progress will lead to improvements upon the probabilities reported here.

\section{PART 1 OF METHOD: BUILDING THE REGIONAL EARTHQUAKE MODEL}

In Part 1 of the calculations, WG99 constructed a model for earthquake occurrence on major faults in the SFBR (fig. 2). First, geologic information on fault geometry and slip rates was combined with alternative fault-segmentation models to define a suite of possible rupture sources for each fault system. An area-magnitude relation was used to calculate a distribution of likely earthquake magnitudes for each rupture source. Next, rupture sources were combined in order to construct a moment-balanced rupture model for the long-term behavior of each fault system. Finally, the rupture-source models for all seven fault systems were combined to form an aggregated, regional model for earthquake occurrence. A Monte Carlo approach was used to construct many such aggregations across the range of uncertainties associated with each observation and calculation step. The known plate-tectonic rate of deformation across the region was used as a constraint, such that realizations violating this rate were thrown out. About $40 \%$ of the aggregated regional models were rejected because they violated this constraint. Those remaining - 2,000 culled realizations of the regional "earthquake machine"-were combined to form the output of Part 1: the mean magnitude and rate of occurrence of each rupture source (table 3 ).

\section{MAJOR FAULTS OF THE SFBR}

The San Andreas Fault system in the SFBR contains faults of different lengths, slip rates, and styles of movement. This heterogeneity results in a broad range of earthquake sizes and rates of occurrence. The WG99 study explicitly modeled faults with slip rates greater than $1 \mathrm{~mm} / \mathrm{yr}$. Faults with lower slip rates are capable of producing moderate to large earthquakes, but the repeat times for these events are measured in thousands of years. Six strike-slip faults in the SFBR are known to be slipping faster than $1 \mathrm{~mm} / \mathrm{yr}$. - the San Andreas, Hayward-Rodgers Creek, Calaveras, San Gregorio, ConcordGreen Valley, and Greenville Faults. These are the faults that, over the long term, release almost all of the seismic moment in the SFBR. Slip rates on these faults range from 2 to $24 \mathrm{~mm} / \mathrm{yr}$, and recurrence intervals for moderate to large events average hundreds of years, short enough for meaningful timedependent probability estimates. In addition, one newly recognized fault source, the blind Mount Diablo Thrust Fault, slips at a long-term rate of about $3 \mathrm{~mm} / \mathrm{yr}$ and is included in the calculations. Thus, there 
were seven fault systems in the SFBR for which the long-term earthquake occurrence was characterized.

\section{SEGMENTATION CONCEPT: FAULT SEGMENTS AND RUPTURE SOURCES}

Two assumptions underlie the regional model: (1) that faults are composed of fault segments that define the location and extent of future earthquake rupture, and (2) that these segments are recognizable from geologic and geophysical data and the rupture in past earthquakes. Although there is uncertainty and controversy surrounding these issues, WG99 adopted the concept of segmentation in its basic fault-characterization strategy. In contrast to WG88 and WG90, WG99 concluded that contiguous segments could rupture in a wide variety of combinations. Accordingly, the WG99 model expands the earlier segmentation concept by incorporating various ways in which the segments may rupture in earthquakes. It also specified the uncertainties in the position of the segment endpoints. Furthermore, it allowed for the possibility of floating earthquakes of specified size but with location unconstrained by the identified segment endpoints.

In the WG99 segmentation model, a fault segment is the basic building block for each fault. It is the shortest section considered capable of repeatedly rupturing to produce large earthquakes. Table 2 lists the 19 fault segments identified by WG99's source-characterization subgroups. Important new observations about the segmentation and behavior and of each fault, and contrasts with prior characterizations, are noted in Appendix B. The seismic width of each segment (depth extent of rupture) was estimated by the lower bound on small earthquake hypocentral depths and from insights from heat flow observations on the depth to the brittle-ductile transition.

A rupture source is a combination of one or more contiguous fault segments that can fail, producing an earthquake. The long-term slip rate of each fault segment is accommodated by its failure in what may be a variety of ruptures, each having its own magnitude and rate of recurrence. This concept can be understood by considering the following example (fig. 3). The Hayward-Rodgers Creek Fault system is assumed to consist of three fault segments: the southern Hayward (SH), northern Hayward (NH), and Rodgers Creek (RC) segments. Each segment may fail alone or in combination with others. These combinations produce six possible earthquake rupture sources, each with an associated mean magnitude (see table 3). In addition, the fault may produce a floating earthquake, in this case taken to be M6.9, or approximately the size of the 1868 earthquake on the southern Hayward Fault. The relative degree to which the long-term fault slip is accommodated by each rupture source was determined by expert opinion within the source-characterization subgroups.

\section{FAULT SLIP RATE AND ASEISMIC SLIP}

Long-term slip rates and their uncertainties were estimated for each fault segment (table 2), principally from paleoseismic data and sometimes also from geodetic measurements and faultkinematics considerations. To account for observed aseismic slip (creep) on some faults in the SFBR, a seismic slip factor, also known as the seismic coupling factor, was introduced in the model. A segment with a seismic slip factor of $\mathrm{R}=1$ accumulates seismic moment at the full geologic rate, while a segment with a factor of $\mathrm{R}=0$ releases all of its geologic moment through creep. The seismic slip factor was used 
to define the area of the fault that stores seismic moment, thereby affecting both the amount of seismic moment released in a rupture and the mean rate of ruptures on a segment, but not the long-term fault slip rate. The relative weighting of the alternative values of the seismic slip factor was prescribed, depending on the degree to which it could be defined by available observations and models.

\section{EARTHQUAKE MAGNITUDES}

The area of each rupture source was used to assign it a mean magnitude, using a set of generic magnitude-fault area (M-A) relations. The Wells and Coppersmith (1994) M-A relation is commonly used for this, but WG99 analysis shows that their relationship systematically underestimates $\mathbf{M}$ for large California earthquakes. Therefore, WG99 has used it together with two other M- $A$ relations - similar in form but corresponding to higher average earthquake stress drops- that seem to better describe the California data. The three relations, and the observational data supporting them, are described in Appendix C. These M- $A$ relations give only the mean magnitude; WG99 also assumed an intrinsic variability in magnitude for a given area, represented by a normal distribution about the mean magnitude with a standard deviation of 0.12 .

The resulting mean magnitudes of earthquakes on characterized rupture sources vary from 6.07 to 7.94 (table 3). Segments on the San Andreas and San Gregorio Faults are long and fully locked; thus, sources on those faults generate earthquakes mostly in excess of magnitude 7.0. Other faults in the region are more highly segmented (e.g., Greenville Fault) and (or) expend some moment in creep (e.g., Hayward, Calaveras, and Concord-Green Valley Faults) and consequently are capable of generating smaller earthquakes in this methodology.

\section{BUILDING MOMENT-BALANCED MODELS FOR EACH FAULT AND FOR THE REGION}

WG99 constructed moment-balanced fault rupture models for each fault system. This was done by combining rupture sources in such a way as to honor their relative likelihood as specified by the expert groups. Adjustments were made to the relative frequency of occurrence for each rupture source such that every fault segment keeps pace with its long-term geologic slip rate. This ensures that all of the seismic moment that accumulates on each segment is released in the earthquakes that rupture it. Each alternative path through the decision tree results in a slightly different moment-balanced model, because its component ruptures combine different branch-point choices of segment geometry, slip rate, seismic slip factor, and moment-area relation.

Each moment-balanced fault model is one valid representation of the fault's long-term behavior and is consistent with the available measurements of slip rate along that fault. An aggregation of seven such models, one for each of the seven characterized faults, forms a potential model of earthquake occurrence for the region as a whole. However, some combinations of valid fault models will nonetheless violate the observed rate of tectonic deformation across the region. Observations of this regional rate are independent of the slip-rate measurements underlying the fault models; thus the regional rate may be used as a constraint. This constraint is applied by requiring that the summed rates of fault slip (from 
earthquakes and creep) on transects across the SFBR are consistent with the measured plate-motion rate of 36 to $43 \mathrm{~mm} /$ year. Each regional aggregation of fault models was checked against this constraint, and those violating it were thrown out.

This process - constructing fault models and checking their aggregation against the regional constraint—was repeated many times until 2,000 aggregations had been collected. These 2,000 culled realizations of the regional earthquake machine were combined to form the output of Part 1: the mean magnitude and rate of earthquakes on each rupture source (table 3). (Information about the distribution of magnitudes and rates about these mean values is also preserved, but is not presented here.)

The mean rate of earthquakes on a rupture source reflects the fault slip rate, earthquake magnitude (slip per event), and the relative likelihood of that source rupturing as defined by the faultcharacterization groups. The preponderance of rupture sources fail with recurrence intervals of 2,000 years or less. The recurrence interval of events of magnitude near M7.9 simultaneously breaking all four segments of the San Andreas Fault is predicted to be 361 years, whereas events breaking only three of those segments occur in the WG99 model at intervals of $>10,000$ years. Some small earthquakes on the Calaveras Fault have a modeled recurrence interval of less than 100 years.

\section{“BACKGROUND” EARTHQUAKES}

WG99 defined a background earthquake to be an earthquake not associated with any of the seven faults specified in this report. In addition to earthquakes on recognized low slip-rate faults that are not characterized, historical earthquakes have occurred for which no responsible fault has yet been identified. The 1989 M6.9 Loma Prieta earthquake and the 1986 M5.7 Mt. Lewis earthquake are examples of recent historical earthquakes that occurred on faults previously unrecognized.

WG99 used a statistical procedure to estimate the probability of a background earthquake from the available data on earthquake occurrence in the SFBR (Wesson et al., in preparation). Each historical earthquake within the region was considered separately, and a likelihood was calculated that it can be associated with each of the characterized fault segments or with none of them (i.e., associated with the background region). This procedure, based on Bayesian inference, took into account the location of the earthquake and associated uncertainty, the locations of the fault segments, and the level of activity of each fault as determined from its slip rate. Earthquakes were taken from three catalogs: the catalog of large earthquakes from 1836-1998 (Bakun, 1999), the UC Berkeley Historic Earthquake Relocation Project (HERP) catalog of earthquakes from 1951-1998 (Uhrhammer, in preparation), and the Northern California Seismic Network catalog (NCSN) from 1984-1997 (Northern California Data Center, http://quake.geo.berkeley.edu). The earthquakes associated with the background were found to be consistent with a Gutenberg-Richter relation

$$
N(M)=10^{a-b M}
$$

where $N$ is the number of earthquakes with magnitude greater than $M$ and $a$ and $b$ are dimensionless parameters. Applying a Poisson model to these results, WG99 estimates the probability of at least one M6.7 or larger background earthquake in the region in the next 30 years to be 0.09. 


\section{CONSISTENCY CHECKS ON THE REGIONAL MODEL}

There are several ways the regional model can be checked for consistency. WG99 compared the magnitude-frequency distribution of earthquakes derived from the model to that observed in the SFBR. It also compared the combined mean rates for all rupture sources in the regional model to the observed historical regional rate of earthquakes above a prescribed magnitude threshold of M6.7. These comparisons provide useful checks on the assumptions and methodology that went into the regional model. Credence in the assumptions, models, and data brought together here are bolstered if the calculated regional activity resembles the historical regional seismicity or differs from it in an understandable way.

Magnitude distribution. The earthquake distributions for all sources in the model may be combined with the calculated rate of background events to form a regional frequency-magnitude relation (fig. 4). This curve has a nearly log-linear portion extending from about M6.7 to M7.7. The log-linear behavior falls off at lower magnitudes because the assemblage of characterized rupture sources is incomplete below that magnitude level. The fall-off at high magnitudes reflects the maximum size of earthquakes in the model and the upper tail of their assumed distribution.

The calculated cumulative rates $(\mathbf{M} \geq 6.5)$ were fit by a least-squares method to a Gutenberg-Richter distribution $(a=4.51 \pm 0.16, b=0.91 \pm 0.02)$. This value of $b$ is in remarkable agreement with Bakun's (1999) value of $b=0.90$ determined for the SFBR. This result is not guaranteed by the methodology - the regional slip-rate constraint, along with assumptions about aseismic processes, serve to calibrate the regional rate of earthquakes, but no explicit constraint was imposed in the methodology to control the resulting distribution of earthquake magnitudes. While this result might be, in part, fortuitous, it suggests that the rupture sizes and frequencies used as input to the calculation sequence are consistent with the observed regional seismicity.

Historical regional earthquake rates. WG99 estimated the historical rates of $\mathrm{M} \geq 6.7$ earthquakes in the region in the 19th and 20th centuries and compared these to the corresponding rates predicted in the regional model (table 4 and fig. 5). For the second half of the 19th century, the regional rates of $M \geq 6.7$ earthquakes were estimated with Bakun's (1999) catalog of historical $M \geq 5.5$ earthquakes by extrapolation, assuming a Gutenberg-Richter distribution of magnitudes. The rate appears to have increased from 1850 to 1905 (fig. 5). The mean annual rate of $\mathrm{M} \geq 6.7$ earthquakes doubled, from 0.04 between 1850 and 1877 to 0.08 between 1878 and 1905. Corresponding rates during the second half of the 20th century were estimated with the instrumental catalog of $M \geq 3$ earthquakes. The 20th-century data were divided into six approximately decade-long, non-overlapping time intervals from 1942 to 1998 (table 4).

A sharp contrast in regional activity level in the pre- and post-1906 periods has been noted by many authors (see fig. 6). This contrast has been variously attributed to a pre-1906 "run-up" in seismicity (Jaumé and Sykes, 1996, Bufe and Varnes, 1993, Sammis et al., 1996), to a regional drop in stress level due to the large slip in the 1906 earthquake (the so-called post-1906 "stress shadow," Harris and Simpson, 1998), and to both. The contrast is clearly seen in the rate estimates as well (fig. 5). 
The historical and contemporary regional rates provide context for the mean rates calculated in the WG99 model. The mean regional rate for $\mathbf{M} \geq 6.7$ earthquakes on all rupture sources in the calculation sequence is shown as a heavy dashed line in fig. 5. The 5th and 95th percentile values in the model calculations are shown as light dashed lines. The predicted rate lies between the pre-1906 rate and the contemporary rate. Since the calculated mean rate describes the long-term fault behavior and does not explicitly include a 1906-stress-shadow effect, the fact that it falls between the pre-1906 and contemporary levels is consistent with its representing the average rate over a complete seismic cycle.

For a further comparison, two additional estimates of the regional rate of $\mathbf{M} \geq 6.7$ earthquakes are shown as dotted lines in fig. 5. Andrews and Schwerer (1999) solved for frequencies of events on a system of fault-segment combinations generalized from fault segments identified by WGNCEP, and balanced for regional slip rate. The resulting cumulative regional annual rate of $\mathbf{M} \geq 6.7$ earthquakes in this model is 0.054. Ward (1999) estimated long-term regional earthquake rates with a 3,000-year computer simulation of a physical earthquake model of the SFBR and found a cumulative annual rate of 0.043 for $\mathbf{M} \geq 6.7$ earthquakes.

\section{MEAN RUPTURE RATES ON FAULT SEGMENTS}

The long-term rates of earthquakes on rupture sources (table 3) also determine the mean rate of rupture of each fault segment in earthquakes. The rate of segment rupture is simply equal to the combined rates of those rupture sources that include the segment. Floating earthquakes are added in proportion to the length of the segment relative to the total length of all segments that share the same floating earthquake. The summed number is the mean rate of earthquakes on the segment, and its inverse is the mean time between earthquakes. For example, the rate of rupture of the Rodgers Creek Fault segment is equal to the sum of the rates of four sources: the Rodgers Creek by itself (RC), the combined rupture of the Rodgers Creek and the Northern Hayward $(\mathrm{RC}+\mathrm{NH})$, the rupture of the entire fault $(\mathrm{RC}+\mathrm{NH}+\mathrm{SH})$, and a portion of the rate of floating earthquakes of M6.9.

More specifically here, WG99 is interested in the rates of segment rupture in earthquakes above a threshold magnitude $\mathbf{M} \geq 6.7$, because those rates will be used to calculate 30-year probabilities in Part 2, below. Thus, only included in the totals are those rupture sources that produce earthquakes above that threshold size. For those sources straddling M6.7, WG99 included a pro-rated portion of their rates according to the distribution of earthquake magnitudes produced by that source.

Table 5 shows the long-term mean rates of segment rupture in $M \geq 6.7$ earthquakes and their inverses, the average recurrence intervals. Ruptures of the San Andreas Fault are expected most frequently, with an average of 212 to 220 years between ruptures along any of its four segments. As longer and more complete paleoseismic data becomes available for the faults in the SFBR, it will be possible to use the measured rate of earthquakes to test and refine the WG99 fault-rupture models. 


\section{PART 2 OF METHOD: CALCULATING 30-YEAR EARTHQUAKE PROBABILITIES}

The first part of the calculation sequence defined a regional earthquake model or, more correctly, a suite of regional models for the long-term earthquake behavior of the regional fault system. If WG99 were interested solely in the long-term behavior of the fault system, calculations could stop at this point. However, WG99 is concerned with earthquake probabilities over times scales that are much shorter than the mean recurrence interval of any of the faults. Accordingly, the probability that any particular event will occur is low. With a 30-year period, it is possible to make meaningful forecasts with respect to the hundred-year-plus recurrence intervals of large earthquakes in the region, while keeping the forecast window short enough to guide important choices regarding earthquake safety, such as retrofitting homes or major structures and modifying building codes.

Making forecasts of earthquake probabilities for the next 30 years requires a probability model for earthquake occurrence. The probability model describes how earthquakes are distributed in time. WG99 chose to focus on models that describe the probability for fault segments rather than the probability for rupture sources. This choice is in keeping with WG88 and WG90, which considered earthquake probabilities on a segment-by-segment basis. The present situation is somewhat more complicated, as WG99 explicitly introduced multiple modes of failure for all segmented faults. Consequently, WG99 determines both the probability that an earthquake will rupture a segment, regardless of where it initiates, and the probability that an earthquake will initiate on the segment, regardless of where it propagates.

For segment ruptures, WG99 models the series of events on each fault segment as an independent renewal process. In a renewal process, the times between successive events are considered to be independent and identically distributed random variables. This is to say that the occurrence probability of the next event only depends upon the time since the last event, parameters of the renewal process, and of course the time interval of interest. Each renewal model is specified by a probability density function that defines the chance that failure will occur in the infinitesimal interval from $t$ to $t+\Delta t$, where $t$ is time measured from the date of the last earthquake (fig. 7).

The model is further simplified by reducing the complex physical process of the earthquake machine to a point-process model (Cox and Lewis, 1966), in which the failure condition of the fault is described by a single state variable that rises from a ground state to the failure state during the earthquake cycle. When a rupture occurs on the segment, it resets the renewal process to its initial state. Evolution of the point-process model toward failure is governed by the time independent parameters that pertain to the specific segment, and by certain global parameters.

To compute the probability that an earthquake will initiate on a segment, WG99 employs the timepredictable model (Shimazaki and Nakata, 1980). In the time-predictable model, the time to the next event is equal to the time required to restore the fault to the same stress state it was in when the preceding earthquake occurred. Again, a point-process model is used to represent the physics of the earthquake and loading cycle. The time-predictable model requires knowing the slip in the last event, information that is available only for the San Andreas Fault and the Southern Hayward Fault segment. 
The principal probability values presented in this report for the period 2000 to 2030 are conditional probabilities. These give the probability that one or more earthquakes will occur on the rupture source in question during the 30-year interval from 2000 to 2030, conditional upon such an earthquake not having occurred by the beginning of the year 2000. The calculation of conditional probability follows standard statistical methodology, as described in WG88 and WG90. The conditional probability is determined by dividing the area under the density function in the interval of interest by the area of the density function at times equal to or greater than the start of the interval of interest (fig. 7).

The remainder of this section describes the specifics of the models used to compute conditional probabilities. Each model forms a branch in the calculation sequence. Calculations for each model are carried out independently all the way to the computation of the combined earthquake probabilities for the SFBR. As a final step, expert opinion is used to weight the model results in order to obtain an aggregate, preferred set of probability values. In the following paragraphs, the models are introduced in order, from the least complete to the most complete description of the physics of the earthquake cycle.

\section{EXPONENTIAL MODEL}

The exponential model describes the distribution of times between successive events for a homogeneous Poisson process (random occurrence). This renewal process model has the important property that the rate at which earthquake are expected to occur is constant over time. Thus, it has no "memory" of the time of the last event. The conditional probability in the Exponential (or Poisson) model is also independent of the time of the last event. The only parameter required to completely specify the exponential model is the mean rate of earthquake occurrence.

This probability model has long been the standard model for probabilistic seismic-hazard analyses, most recently in the Seismic Shaking Hazard Maps of California (Petersen et al., 1996). It is most appropriate when no other information than the mean rate of earthquake production is known. It is at odds, however, with physical models of the earthquake source, in which the tectonic stress released when a fault fails must rebuild before the next earthquake can occur at that location. As did previous working groups, WG99 prefers models of earthquake occurrence in which the probability of an earthquake is related to the state of stress along the rupture segment and increases as the stress recovers.

\section{BROWNIAN PASSAGE TIME (BPT) MODEL}

In contrast to the "memoryless" exponential model, other forms of renewal process models can embody the expectation that following one earthquake another is unlikely until sufficient time has elapsed for stress to gradually re-accumulate. Such models require a minimum of two parameters: the mean recurrence interval and the variability of recurrence intervals. WG99 defines this variability of recurrence times as the aperiodicity, which is equal to the standard deviation of recurrence time divided by the mean recurrence time, also known as the coefficient of variation. Knowledge of the date of the last event is also required for some renewal models. 
The specific time-dependent renewal model used by WG99 is the Brownian Passage Time model (BPT) recently proposed by Matthews (1999) and Ellsworth et al. (1998) to describe the statistical distribution of rupture times. Matthews (1999) derived the BPT distribution by adding Brownian perturbations to a steady tectonic-loading process in which rupture occurs when a critical failure threshold is reached. The earthquake relaxes the stress to a characteristic ground level, beginning a new failure cycle. This model of a Brownian relaxation oscillator provides a connection between the time intervals separating events and a formal state variable that reflects the macroscopic mechanics of stress accumulation and release. It enables the calculation of the probabilities following the perturbation of the stress state by an external event, such as the regional effects of the stress release in the Great 1906 San Francisco Earthquake. The influence of such interactions on recurrence times is transient and strongly depends on when in the loading cycle the perturbation occurs.

Aperiodicity. For the aperiodicity, WG99 used three (weighted) values: 0.3, 0.5, and 0.7. These values were found to be representative of aperiodicities for 37 earthquake sequences with magnitudes between -0.7 and 9.2 analyzed by Ellsworth et al. (1998). The bounding values of 0.3 and 0.7 correspond to failure processes that are respectively more regular and more irregular than the global average. These values are similar to the coefficient of variation of $0.5 \pm 0.2$ used by SCEC in its Phase II report.

Date of last event. Geological and historical information gives a definite date of last rupture for some fault segments, a range of permissible dates for other fault segments, and a bounding date in most cases (table 2). The bounding date is taken as A.D. 1776, the founding date of Mission Dolores in what is now San Francisco, and the date after which it is believed that the historical record for northern California is complete for earthquakes above about M7 (Toppozada and Borchardt, 1998).

When the date of the last rupture event is unknown, WG99 assumes that the rupture source was in a steady state in 1776, with an earthquake rate equal to that of the corresponding exponential model. If no earthquake has occurred on a fault segment in the open interval of 224 years since 1776, this valuable information that can be used to improve the earthquake probability estimate. A theory that includes the open interval was developed by Matthews (1999) for the BPT model.

Stress transfer. The occurrence of an earthquake redistributes stress throughout the region (Stein, et al., 1997; Toda, et al., 1998). A sufficiently nearby and large earthquake may, depending on geometry, move a fault segment closer to failure if the stress increases, or further from failure if the stress decreases. WG99 introduced stress perturbations from nearby earthquakes where they were found to be significant. Although there are a number of means by which the effect of stress transfer on failure time may be calculated, WG99 used the straightforward approach of converting the average Coulomb stress change on a fault segment into an equivalent time change by dividing it by the loading rate. For example, a drop in stress of 1 bar on a fault segment that is being loaded at a rate of 0.1 bar/year produces a "clock change" of -10 years. Stress perturbations associated with the 1906 were large and affected faults throughout the region; the range of values shown in table 6 reflect the wide variety of physical models currently being considered for the link between Coulomb stress change and the earthquake failure process. The M6.9 Loma Prieta earthquake in 1989 had a more local effect of markedly dropping the stress level on the nearby Santa Cruz Mountains segment of the San Andreas 
Fault and more modestly raising the stress on the Peninsula segment. WG99 models the effects of the 1989 event as a clock change of -60 years and +5 years on those two segments, respectively.

Two parallel calculations were run on the entire suite of faults using the BPT model. One ignored stress-transfer effects, while the other used the clock-offset values. Results are presented below for both calculations.

Earlier Working Groups used the lognormal model (Nishenko and Buland, 1987) as a generic recurrence model for earthquake forecasting. The shape of the probability density function of the lognormal model is very close that of the BPT model, although the behavior of the two models diverges at times that are long compared to the mean return time (Ellsworth et al, 1998). The main advantages of the BPT model for WG99 is its ability to compute probabilities when the date of the last event is unknown.

Application of the BPT model. The BPT model was applied to each of the 19 segments using the mean rates of occurrence from table 5. This gives the 30-year probability of an earthquake involving the segment. WG99 then folded this back together with information about the relative likelihood of the various rupture sources in order to determine the probability for the fault as a whole.

\section{TIME-PREDICTABLE MODEL}

The third and final model is the time predictable. In this model, the next earthquake occurs when the stress released in the last event is restored by tectonic loading, just as with the BPT model. The principal difference between these models is that in the time-predictable model, the state after an event depends on the size of that event, whereas in a renewal model the state is independent of the size of the last event. In other words, the amount of time required to rebuild stress to the failure point depends on how much stress was released in the last event. In constructing the time-predictable model, WG99 set the distance between the ground state and failure state equal to the average stress drop on the segment in the last rupture event, and used the BPT model to evolve the stress state with time toward failure. As with the BPT model, other earthquakes were allowed to perturb the stress state, which is done by perturbation to the state variable, rather than by a clock offset.

Information required for the time-predictable model is the date of the last event, the slip distribution on the fault, the stressing rate, and the aperiodicity. The slip distribution in the last event determines the mean stress drop on the fault. Dividing the stress drop by the stressing rate yields the expected time of the next earthquake. Slip values are available only for the San Andreas Fault in the 1906 earthquake (Thatcher et al., 1997) and the southern Hayward Fault segment in the 1868 earthquake (Yu and Segall, 1996). Consequently, these are the only faults modeled with the time-predictable model.

Application of the time-predictable model. This model was applied to the four segments of the San Andreas Fault and to the southern segment of the Hayward Fault. For each fault segment, the stress drop in the resetting earthquake was determined using a probabilistic description of fault slip in the event. Similarly, the stressing rate was also defined by a probability distribution, and their quotient gives a distribution of expected times for the next event. For the San Andreas Fault, the state variable of 
the corresponding BPT model was perturbed in 1989 by the stress transferred to each segment by the Loma Prieta earthquake. In the case of the southern Hayward Fault segment, the stress perturbation of the 1906 earthquake was applied to the state variable. The resulting probabilities correspond to the odds that the epicenter of a future event will fall on each segment. This is not the same as the segment rupture probabilities determined with the exponential and BPT models, as they give the odds that the segment will rupture in any earthquake. The time predictable probabilities are converted into segmentrupture probabilities and fault-rupture probabilities by considering the relative odds that an event starting on one segment will stop or continue to propagate into other segments.

\section{PROBABILITY CALCULATION RESULTS}

WG99 estimated the likelihood of the occurrence of one or more large ( $M \geq 6.7)$ earthquakes during the period from 2000 to 2030 in the SFBR by calculating three sets of quantities:

1. The probability that the region will experience a large earthquake (tables $\mathbf{1}$ and $\mathbf{8}$ ).

2. The probability that each fault will produce a large earthquake (tables $\mathbf{1}$ and $\mathbf{8}$ ).

3. The probability that each fault segment will rupture in a large earthquake (table 7)

Conditional probabilities were calculated using each of the probability models described above. Fifteen members of a WG99 oversight group judged the appropriateness of each model on each fault segment by considering the quality of data on that fault segment and the appropriateness of the model and assigned weights to each method accordingly. The weighted mean probabilities are referred to as experts' weighted aggregate 30-year probabilities and are shown in the right-most columns of tables 7 and 8. These may be treated as preferred values.

\section{REGIONAL PROBABILITY}

The probability of one or more large earthquakes in the SFBR in the next 30 years is estimated to be 0.70 . This result is similar to the WG90 regional estimate of 0.67 , and the uncertainty in the WG99 result $(1$ standard deviation $=0.1)$ includes the WG90 regional estimate. The present result incorporates a broader range of inputs than was considered in WG90, including new or revised information on the San Andreas, Hayward-Rodgers Creek, Calaveras, Concord-Green Valley, San Gregorio, Greenville, and Mt. Diablo Faults. The regional probability incorporates the effects of the 1906 "stress shadow" and also a probability of 0.09 that at least one M6.7 or larger earthquake will occur on a fault not characterized in this report (e.g., on the Great Valley thrust or on one of the lowslip-rate thrust faults that accommodate contraction across the southern Santa Cruz mountains). 


\section{FAULT PROBABILITIES}

The Hayward-Rodgers Creek Fault system has the highest 30-year probability, 0.32. The next highest probability is for the San Andreas Fault, whose lower probability, 0.21, reflects both the larger magnitude of its earthquakes and its recent relaxation in 1906. Of the faults not previously characterized, the Calaveras Fault has the highest probability, 0.18. To the east of these major faults, earthquake probabilities on the Concord-Green Valley, Greenville, and Mt. Diablo Faults are each individually low. However, in combination with the Calaveras Fault, they represent a probability of about 0.30 for a large earthquake in the rapidly developing areas of eastern Contra Costa and Alameda Counties. Similarly, a combination of the San Andreas and San Gregorio Faults presents the San Francisco Peninsula and communities along the Pacific coast with a probability of a large earthquake of 0.29. It should be noted that there is considerable uncertainty whether the Calaveras Fault can produce earthquakes of $\mathbf{M} \geq 6.7$ or fails predominantly with moderate earthquakes and creep.

An important conclusion of this study, then, is that the potential for large earthquakes is dispersed throughout the region. This was recognized by WG88 and WG90, but not quantified. Faults capable of producing earthquakes of $\mathbf{M} \geq 6.7$ are widely distributed across the SFBR.

\section{SEGMENT PROBABILITIES}

A key comparison between the results of WG99 and of previous reports involves probability estimates for individual fault segments. WG99 calculated the probabilities that each fault segment would be involved in a large earthquake (table 7). These probabilities may be compared to results obtained by WG90 for segments of the San Andreas, Hayward, and Rodgers Creek Faults.

For the northern and southern Hayward Fault segments, the preferred probabilities are 0.16 and 0.17 , respectively. These values compare with 0.28 and 0.23 assigned by WG90. The decrease in probabilities is due in part to the use of new geologic information about the Hayward Fault, including a longer estimated mean recurrence time and a new understanding of the role of aseismic slip (fault creep), as well as the shadowing effect of the 1906 earthquake. New information on the timing of the most recent large earthquake on the Rodgers Creek Fault, coupled with the effects of the 1906 stress shadow, has led to a preferred probability of 0.20 , nearly equal to the value of 0.22 reported by WG90.

The San Andreas segment rupture probabilities also differ from the WG90 result. Results may be compared despite differences in placement of segment endpoints. Probabilities for the two segments on the California coast north of San Francisco have increased because of the use of different segment definitions, higher slip rates, the possibility that ruptures from outside these segments can propagate into them, and the use of the floating earthquake. These latter two factors were not considered by WG90. The probability for the Santa Cruz Mountains segment also increased from $\sim 0$ to 0.10 , reflecting, in part, the decision to consider the 1989 Loma Prieta earthquake to have occurred on a separate, albeit nearby, fault, in addition to the waning effect of the 1989 earthquake since 1990 and allowance for multiple-segment ruptures initiating farther north. The 30-year probability for the peninsula segment dropped a small amount, from 0.23 to 0.15 , primarily reflecting a lower slip rate and, consequently, a longer mean repeat time for this fault segment. 


\section{PROBABILITY OF SMALLER EARTHQUAKES IN THE SAN FRANCISCO BAY REGION}

In the regional model, fault segments are typically tens of kilometers in length. Because fault segments are the smallest units of the faults that can rupture in the model, the faults thus characterized cannot produce earthquakes smaller than about M6.5. (The minimum magnitude varies over the suite of faults, depending on segment lengths, seismogenic widths, and seismic-slip factors.) However, earthquakes in the range M6.0 to M6.7 can cause significant localized damage, particularly if located under an urban area.

As an extreme example, the January 17, 1994, M6.7 Northridge earthquake, located under a part of greater Los Angeles, caused $\$ 20-40$ billion in damage. All $6.0 \leq \mathbf{M} \leq 6.7$ shocks occurring within the WG99 study region can be expected to cause some, and perhaps considerable, damage. The amount of damage - a few million to a few tens of billions of dollars - will depend on many factors, including the magnitude of the earthquakes and their proximity to metropolitan areas. One way to put bounds on the likelihood of earthquakes in this magnitude range is to look at historical and recent rates of seismicity.

The period from 1968 to 1997, during which high-quality instrumental data on SFBR earthquakes has been collected, offers a possible lower bound on the production rate of $6.0 \leq \mathbf{M} \leq 6.7$ earthquakes, if one assumes that the stress-shadow effects of 1906 are still wearing off. The period from 1850 to 1906 was seismically the most active in the historical record and can offer a possible upper bound. Seismicity models for these periods (Bakun, 1999) suggest a probability between 0.80 and 0.99 , respectively, of at least one $6.0 \leq \mathbf{M} \leq 6.7$ earthquake in the next 30 years. The period from1968 to 1997 period is arguably the most relevant one from which to extrapolate into the next 30 years, because it reflects the most recent activity; therefore, .080 is WG99's preferred value.

\section{FUTURE DIRECTIONS}

WG99 anticipates that the results and methods described in this report will continue to evolve as better data on the SFBR's faults become available and as new concepts on the physics of earthquakes develop.

The concept of a regional model, first attempted in the 1995 SCEC Phase II report, has been at the core of the WG99 effort. WG99 expects that future reports will continue to use regional models and that research will be needed to compare and contrast different approaches to formulating such models.

One goal of WG99 has been to develop a methodology that would allow probability results to be readily updated as new data become available. WG99 believes it has partly succeeded in this goal by formalizing the application of expert opinion and by capturing many of the calculational steps into a single computer program with well-defined inputs and outputs. This allows for new data values to be entered and for sensitivity analyses to be conducted to explore the importance of input values and assumptions. WG99 expects that more can be done along these lines, and that the goal is one worth pursuing. 


\section{APPENDIX A: WORKING GROUP PARTICIPANTS}

The Working Group on California Earthquake Probabilities 1999 (WG99) solicited the participation and open discussion of the earthquake research community. Participants included scientists from Federal and California State government, private industry, consulting firms, and academia.

These persons provided leadership in the process:

David Schwartz, Chair....................U.S. Geological Survey

Norm Abrahamson......................... Pacific Gas \& Electric

William Bakun ............................ U.S. Geological Survey

Michael Blanpied .......................... U.S. Geological Survey

Chris Cramer................ Calif. Div. of Mines and Geology

James Dieterich ............................U.S. Geological Survey

William Ellsworth .........................U.S. Geological Survey

William Foxall ...........................Lawrence Livermore Labs

Thomas Hanks ............................. U.S. Geological Survey

Kathryn Hanson............................ Geomatrix Consultants

Thomas Henyey ........................... Univ. of Southern Calif.

Keith Kelson ................................William Lettis \& Assoc.

William Lettis..............................William Lettis \& Assoc.

James Lienkaemper...................... U.S. Geological Survey

Mark Petersen ............... Calif. Div. of Mines and Geology

Paul Reasenberg............................U.S. Geological Survey

Robert Simpson ............................U.S. Geological Survey

Jeffery Unruh.............................William Lettis \& Assoc.

Mary Lou Zoback ......................... U.S. Geological Survey 
The following persons also participated in the Working Group:

Joe Andrews

U.S. Geological Survey

Michael Angell. Geomatrix

John Baldwin William Lettis \& Assoc.

Roger Bilham. University of Colorado

Jack Boatwright U.S. Geological Survey

Glenn Borchardt, Soil Tectonics

William Bryant. Calif. Div. of Mines and Geology

Roland Bürgmann Univ. California Berkeley

John Caskey..... ..San Francisco State Univ.

Trevor Dumitru Stanford University

Clark Fenton URS Greiner Woodward Clyde

Jacob Fink Univ. California Berkeley

Sean Ford Univ. California Berkeley

Tom Fumal. U.S. Geological Survey

Eric Geist U.S. Geological Survey

Joan Gomberg. U.S. Geological Survey

Russell Graymer U.S. Geological Survey

Tim Hall Geomatrix

Ruth Harris U.S. Geological Survey

Suzanne Hecker U.S. Geological Survey

James Hengesh Dames \& Moore

Tom Hildenbrand U.S. Geological Survey

George Hilley Arizona State U.

Christopher Hitchcock, William Lettis \& Assoc.

Robert Jachens U.S. Geological Survey

Angela Jayko. U.S. Geological Survey

Keith Knudsen William Lettis \& Assoc.

Steve Kirby U.S. Geological Survey

Allan Lindh U.S. Geological Survey

David Manaker. U.S. Geological Survey

Mark Matthews Walden Consulting 
Andy Michael..............................U.S. Geological Survey

Tom McEvilly Univ. California Berkeley

Robert McLaughlin U.S. Geological Survey

Robert Nadeau Lawrence Berkeley Labs

Tina Niemi University of Missouri

Stuart Nishenko ..Federal Emergency Management Agency

David Oppenheimer U.S. Geological Survey

Tom Parsons U.S. Geological Survey

David Ponce U.S. Geological Survey

Will Prescott U.S. Geological Survey Michael Reichle...... California Division of Mines \& Geol. Stephanie Ross. U.S. Geological Survey

Paul Segall Stanford University

Gary D. Simpson William Lettis \& Assoc.

Wayne Thatcher. U.S. Geological Survey Tousson Toppozada Calif. Div. of Mines \& Geol.

Robert Uhrhammer Univ. California, Berkeley

John Wakabayash.... Independent Consultant

Felix Waldhauser. U.S. Geological Survey

Steve Ward. ..University of California Santa Cruz

Janine Weber-Band Failure Analysis

Donald Wells Geomatrix

John R. Wesling Geomatrix

Steve Wesnousky. University of Nevada Reno

Robert Wesson U.S. Geological Survey

Colin Williams U.S. Geological Survey

Patrick Williams. Univ. California, Berkeley

Chris Wills .......California Division of Mines and Geology Ivan Wong, URS Greiner Woodward Clyde Robert Wright Harlan Tait Associates 
Thanks are due to the following, who helped in various ways to facilitate WG99's work:

Sara Boore

Jane Ciener

Michael Diggles

Carolyn Donlin

Maureen Dowd

Karl Gross

Scott Haefner

James Hendley, II

Christine Jorgensen

Susan Mayfield

Patricia McCrory

Ellen Myren

Clarissa Nixon

Joel Robinson

Nancy Sandoval

Peter Stauffer

Steve Walter

Carl Wentworth 


\section{APPENDIX B: GEOLOGIC AND GEODETIC INPUT DATA}

Fault slip rates, the segmentation model for each fault, and the date of the most recent large earthquake are the critical pieces of information required to characterize behavior of the SFBR faults. Slip rates provide a basis for calculating earthquake recurrence intervals. Segmentation models define potential rupture lengths and are inputs to earthquake magnitude. The most recent event is used in timedependent probability calculations. These data were assembled by expert source-characterization groups consisting of geologists, geophysicists, and seismologists evaluating the information available for each fault. Table 2 lists important fault parameters, including the number of segments, segment lengths, slip rates, seismogenic width, the date of the most recent large earthquake, the seismic slip factor, and the calculated 1906 clock advance. All of these parameters are used in the WG99 model. Important new observations about each fault, and contrasts with the prior WG90 and WGNCEP96 characterizations, are summarized below.

San Andreas Fault. New paleoseismic slip rates define a slip-rate gradient along the fault with the geologic slip rate decreasing from $24 \pm 3 \mathrm{~mm} / \mathrm{yr}$ north of the Golden Gate to $17 \pm 4 \mathrm{~mm} / \mathrm{yr}$ on the San Francisco Peninsula and southward (Schwartz et al., 1998; Hall et al., 1999). This is in contrast to a uniform slip rate of $19 \pm 4 \mathrm{~mm} / \mathrm{yr}$ used by WG90. This change affects the recurrence intervals calculated in this report. Earthquake dates from trenches along the 1906 rupture suggest a rupture similar in length to 1906 occurred in the early to middle 1600's (Schwartz et al., 1998); this observation has contributed to the idea that much of the seismic moment released by the San Andreas Fault occurs primarily during large events.

WG99 has built upon the WGNCEP segmentation model and divides the northern San Andreas Fault into four major segments. From north to south these are the North Coast north (NCN), North Coast south (NCS), Peninsula (P), and Santa Cruz Mountains (SC). The segments and their boundaries are shown on fig. 2. Newly modeled geodetic measurements of the 1906 rupture now indicate a major slip step in the Golden Gate area (Thatcher et al., 1997). This is an important basis for increasing the length of the Peninsula segment and extending its northern boundary to the Golden Gate. In addition, aeromagnetic, seismic-reflection, and microseismic normal-faulting data indicate a 3km right step in the San Andreas Fault offshore from Golden Gate Park (Zoback et al., 1999). This right step has been a persistent feature of the San Andreas Fault for 3 my (Wakabayashi and Hengesh, 1995) and is and additional basis for revising the location of this segment boundary.

San Gregorio Fault. Slip rates and information on earthquake recurrence along the San Gregorio Fault have been difficult to obtain because the fault is offshore for much of its length, with only relatively short on-land strands available for study. Perhaps the most important new finding is from trenching studies at Seal Cove, which show that the fault has clearly generated two large surfacefaulting earthquakes (slip $\geq 3 \mathrm{~m}$ ) at this location during the past 600 to 1380 years (Simpson et al., 1998). 
Multiple strands increase the difficulty of obtaining estimates of full slip rates across the entire fault zone. At Seal Cove, mapping and trenching of a paleochannel of San Vicente Creek offset 300-360 m suggest a slip rate of $3.5 \mathrm{~mm} / \mathrm{yr}$ to $4.5 \mathrm{~mm} / \mathrm{yr}$ over the past 80,000 to 85,000 years for the eastern trace of the fault (the Seal Cove strand) (Simpson et al., 1998). This slip rate is a minimum estimate, because an offshore western strand of the San Gregorio Fault Zone is geomorphically well expressed. Farther south, Weber (1980) and Weber and Nolan (1995) have reported slip rates of 4-11 mm/yr across the entire zone at Pt. Año Nuevo during the past approximately 100,000 years. At present there are no late Holocene slip rates comparable to those available for other SFBR faults. An additional possible constraint on a late Holocene rate is derived from the San Andreas slip-rate gradient. The San Gregorio Fault intersects the San Andreas offshore of the Golden Gate. The San Andreas slip rate decreases from 24 to $17 \mathrm{~mm} / \mathrm{yr}$ across the Golden Gate from north to south. This $7 \mathrm{~mm} / \mathrm{yr}$ slip difference does not appear to be transmitted eastward to the Hayward Fault and is most reasonably partitioned onto the San Gregorio Fault. On these bases, WG99 adopts a slip rate for the northern San Gregorio Fault of 7 $\pm 3 \mathrm{~mm} / \mathrm{yr}$. Although there are clearly uncertainties, this accounts for conservation of slip rate among the San Gregorio and San Andreas Faults, as well as for the range of published slip rates.

The slip rate for the southern San Gregorio Fault is even more problematic, because no part of the fault is exposed on shore. Based on the likelihood that some slip is being transferred onshore to other faults south of Monterey Bay, and that the slip rate on the San Simeon-Hosgri Fault system may reflect that of the San Gregorio, WG99 assigns the southern San Gregorio a slip rate of $3 \pm 2 \mathrm{~mm} / \mathrm{yr}$.

WG99 divided the San Gregorio Fault into a northern and southern segment. Recognizing the uncertainty of this division,WG99 also considered the possibility of a floating earthquake with magnitude M6.9.

Hayward-Rodgers Creek Fault System. Measurements of slip rate for the Hayward-Rodgers Creek Fault have remained stable at $9 \pm 2 \mathrm{~mm} / \mathrm{yr}$ (Lienkaemper and Borchardt, 1996; Schwartz et al., 1993). However, new historical seismicity and paleoseismic data affect interpretation of timing of the most recent event. An earthquake in 1836, previously attributed to the northern Hayward Fault and used in the WG90 calculations, is now placed south of San Francisco Bay (Toppozada and Borchardt, 1998; Bakun 1999). Paleoseismic observations from El Cerrito and the historical record suggest the most recent large northern Hayward event occurred between 1640 and 1776 (HFPEG, 1998), which is similar to the age range of 1670 to 1776 for the last major earthquake on the Rodgers Creek Fault. Preliminary paleoearthquake dates from trenches across the southern Hayward Fault in Fremont (Williams, 1992) and the northern Hayward fault in El Cerrito (HFPEG, 1999) suggest minimum repeat times of 150-250 years and >270-710 years, respectively. Geodetic analysis of the 1868 southern Hayward earthquake (Yu and Segall, 1996) indicate an average slip of $1.9 \mathrm{~m}$, which is larger than the slip value used by WG90. Both the paleoseismic recurrence and higher 1868 slip values support the longer segment repeat times developed in the WG99 report.

The Hayward-Rodgers Creek Fault retains three segments in the WG99 report. These are the southern Hayward (SH; source of the M6.9 1868 earthquake), the northern Hayward (NH), and the Rodgers Creek (RC). The best-estimate 50-km rupture length for the 1868 event (Yu and Segall, 1996) is longer than the southern Hayward segment as defined by WG90. As a result, the northern Hayward 
segment is shortened in the WG99 analysis, with the likelihood of an overlap zone along the two Hayward segments.

Calaveras Fault. Slip rates are now available for the Calaveras Fault. These are based on both paleoseismic and creep observations. The slip rate on the Calaveras Fault changes significantly where the Hayward Fault splays from it. The rates for the northern Calaveras Fault are based on offset channel margins at Leyden Creek that yield a slip rate of $5 \pm 2 \mathrm{~mm} / \mathrm{yr}$ for the past 2,300 years (Kelson et. al, 1996) and a $6 \mathrm{~mm} / \mathrm{yr}$ creep rate on a geodetic net at Calaveras Reservoir (Prescott and Lisowski, 1983). Simpson et al. (in press) have developed a late-Holocene slip rate at Welch Creek of $6 \pm 2$ $\mathrm{mm} / \mathrm{yr}$. Based on these, WG99 uses the rate of $6 \pm 2 \mathrm{~mm} / \mathrm{yr}$ for this fault segment.

Rates for the central Calaveras Fault are less well constrained. The average creep rate for 1968 to 1999 is 16 mm/yr (J. S. Galehouse and J. Lienkaemper, unpub. data, 1999), although this value includes slip possibly increased by stress effects of the 1984 Morgan Hill and 1989 Loma Prieta earthquakes (Galehouse, 1997; J.J. Lienkaemper, writ. commun., 1999). Measurements made since 1997 provide an average rate of $13.5 \mathrm{~mm} / \mathrm{yr}$ (J.S. Galehouse, written comm., 1999). Similar rates are observed at San Ysidro Creek, $5 \mathrm{~km}$ southeast of Coyote Lake, where dating of offset buried stream channels provides a preliminary geologic slip rate of $14 \pm 5 \mathrm{~mm} / \mathrm{yr}$ for the past 4,000 years (Kelson et al, 1998). Based on these new observations, the WG99 slip rate for the central Calaveras segment is 15 $\pm 3 \mathrm{~mm} / \mathrm{yr}$. WG99 extends this rate south to cover the shorter southern segment.

The WG99 segmentation model identifies three segments on the Calaveras Fault. These are a northern segment extending from Calaveras Reservoir north to Danville, a long central segment in the Morgan Hill-Gilroy area, and short southern segment near Hollister. The northern segment displays clear paleoseismic evidence of past large earthquakes. There is a high degree of uncertainty as to whether the central and southern segments can produce large events or fail predominantly with moderate earthquakes and creep (Oppenheimer et al., 1990).

Concord-Green Valley Fault System. Recent paleoseismic investigations of an offset Holocene stream channel at Galindo Creek on the Concord Fault (Borchardt, 1999) yield a slip rate of $3.4 \pm 0.3$ $\mathrm{mm} / \mathrm{yr}$ over the past 6,000 years. This site gives us the first geologic slip rate obtained for the fault. This is similar to the 18-year-long average creep rate of $4 \mathrm{~mm} / \mathrm{yr}$ for the Concord Fault segment (J.S. Galehouse, writ. commun., 1998). Creep rates on the Green Valley Fault have averaged $4.9 \mathrm{~mm} / \mathrm{yr}$ for the past 18 years (J.S. Galehouse, writ. commun., 1998). Using these observations, WG99 assigns rates of $4 \pm 2 \mathrm{~mm} / \mathrm{yr}$ and $5 \pm 3 \mathrm{~mm} / \mathrm{yr}$ to the Concord and Green Valley segments, respectively.

WG99 has identified three segments making up this fault system. These are the northern Green Valley, southern Green Valley, and Concord. There is no evidence for a structural discontinuity between the Concord and southern Green Valley segments.

Greenville Fault. Available data on the late Quaternary slip rate of the Greenville Fault are sparse and have significant uncertainties. The fault has traditionally been viewed as having a low slip rate, and Wright et al. (1982) estimated a late Quaternary rate of 0.5 to $0.7 \mathrm{~mm} / \mathrm{yr}$ based on $90 \mathrm{~m}$ of terrace offset during the past 125,000 to 180,000 years. Unruh and Sawyer (1998) proposed that contractional 
deformation in the Mt. Diablo-Livermore area primarily is driven by a restraining step-over between the Greenville and Concord Faults. WG99 currently favors a slip rate of $2 \pm 1 \mathrm{~mm} / \mathrm{yr}$ on the Greenville Fault to satisfy the kinematic model for growth of the Mt. Diablo anticline and related contractional structures in the Livermore area. The fault has strong geomorphic expression over the southern twothirds of it length, and WG99 has divided it into three segments based largely on geomorphic and structural changes. There are no paleoearthquake dates available for the fault.

Mt. Diablo Thrust Fault. The Mt. Diablo blind thrust is a newly recognized earthquake source for the SFBR. Its addition follows the recommendation of a WG99 group empanelled to identify locations of thrust and reverse faults and to estimate slip rates for these structures. Available slip-rate estimates for the Mt. Diablo Thrust Fault are long-term average rates derived from balanced cross-sections and analysis of stratigraphic relations to determine when shortening began. Because deformation most likely began about $5 \mathrm{Ma}$, the total average shortening across the anticline is best approximated by a value of $13.5 \mathrm{~km}$. This yields a preferred WG99 range for the slip rate of $3 \pm 2 \mathrm{~mm} / \mathrm{yr}$. 


\section{APPENDIX C: NEW MAGNITUDE-AREA RELATIONS INTRODUCTION}

The purpose of this note is to propose a new working relationship between the area of an earthquake source and the mean moment magnitude of earthquakes that completely rupture that source. This type of relationship plays a central role in the estimation of long-term behavior of faults in the 1999 report of the Working Group on California Earthquake Probabilities (WG99). The specific relationship developed below is designed to be appropriate for large California strike-slip earthquakes, of the type mainly considered by WG99.

The purpose of this new relationship is neither to provide the "best fit" to the limited data, nor to attempt to settle the debate about the "correct" form of relationships between seismic parameters of ruptures and their geometry. Instead, we begin with the assumption that the area of the rupture source provides a sufficiently robust basis upon which to build a relationship.

The specific form of the relationship that we consider is of the form

$$
\mathbf{M}=k+\log A,
$$

where $\mathbf{M}$ is the moment magnitude, $\mathrm{k}$ is a constant, $\mathrm{A}$ is the area in $\mathrm{km}^{2}$ of the rupture source, and $\log$ is the base-10 logarithm. The choice of the implicit constant multiplicative factor of 1 on $\log \mathrm{A}$ is deliberate, as it gives a so-called "self-similar" scaling of $\mathbf{M}$ with $A$.

In their widely cited study of empirical relationships between magnitude and rupture parameters, Wells and Coppersmith (1994) derived the relationship

$$
\mathbf{M}=3.98+1.02 \log A
$$

for strike-slip earthquakes. They also derived $\mathbf{M}=4.07+0.98 \log A$ for all rupture types. Recently, Somerville et al. (1999) re-examined these relationships using seismic-slip models of earthquakes. They found an unconstrained relationship of

$$
\mathbf{M}=4.39+0.84 \log A,
$$

and a constrained relationship of

$$
\mathbf{M}=3.95+\log A .
$$

Given the near equality of these relationships with the Wells and Coppersmith results, one might ask if there is anything more to do. Unfortunately, as has been argued for some time, the Wells and Coppersmith (1994) magnitude-area relationship performs poorly for large strike-slip California earthquakes (e.g., Dolan et al., 1995). 
The existence of a problem is self-evident in fig. C1, which shows the data of Wells and Coppersmith (1994) together with their equations and those of Somerville et al. (1999). The misfit, although obvious, is not too surprising, as both regression analyses are strongly influenced by earthquakes in the range $6 \leq \mathbf{M} \leq 7$.

\section{DATA}

There have only been seven well-documented strike-slip earthquakes in California of $\mathbf{M}$ about 7 or larger. These are the M7.8 1857 Fort Tejon, M6.91868 Hayward, M7.6 1872 Lone Pine, M7.9 1906 San Francisco, M7.0 1940 Imperial Valley, M6.9 1989 Loma Prieta, and M7.3 1992 Landers earthquakes. Table C1 assembles the estimated magnitudes, seismic moments, and source areas of these earthquakes. It includes the data of Wells and Coppersmith (1994) and Somerville et al. (1999), as well as the results of several recent studies. The other studies are principally based on geodetic models of the earthquakes or, in the case of the 1857 and 1872 earthquakes, field mapping of the ruptures.

In general, the estimated values are in good agreement. Several earthquakes, however, have notable differences. The geodetically determined magnitude of the 1868 Hayward earthquake of Yu and Segall (1996) is substantially larger than the Wells and Coppersmith (1994) value. Stein and Hanks (1998) reinterpreted the geologic data of Beanland and Clark (1994) for the 1872 earthquake, and derived a smaller magnitude. Geodetic estimates of the area of the 1989 Loma Prieta earthquake by Lisowski et al. (1990) and Arnadottir et al. (1992) are significantly smaller than the values used by Wells and Coppersmith and by Somerville et al. (1999). The area of the 1992 Landers earthquake from Somerville et al. is also substantially larger than the other values. These differences reflect the inherent difficulty in creating empirical relationships of this form, and they underscore the necessity of bringing additional constraints to the problem.

The data from all studies in table C1 except for Wells and Coppersmith (1994) are plotted in fig. C2, together with several magnitude-area equations of the form $\mathbf{M}=k+\log A$. When the authors stated confidence limits, or presented alternative models, those points are plotted as well. Also shown in fig. C2 are three vertical lines. They represent the rupture area for the full rupture of the northern San Andreas Fault for the WG99 narrow, average, and wide rupture depths. The line defined by

$$
\mathbf{M}=4.2+\log A
$$

passes through most of the data. It is anchored by the fit to the 1906 earthquake and reasonably fits most of the other events, with the notable exception of the 1872 earthquake and the geodetic estimates of the 1992 earthquake. Perhaps the misfit of these events reflects their long recurrence intervals, because events with long recurrence times have higher than average stress drops (Kanamori and Allen, 1986), and thus should plot above the indicated line.

\section{DISCUSSION}

If we accept the premise that what we have observed in the past is the best predictor of what will happen in the future, then it is clear from figs. C1 and C2 that the Wells and Coppersmith magnitude- 
area relationship can be expected to systematically underestimate the magnitude of future large strike slip earthquakes in California. Because the long-term rate of earthquakes in the WG99 model is proportional to the average slip, systematic errors in $\mathbf{M}$ have an enormous effect on recurrence time, as slip is proportional to 10 raised to the power $(1.5 \mathrm{x} \mathrm{dM})$.

Based on these considerations, WG99 employs three magnitude-area equations. These are shown on fig. C2 and correspond to the Wells and Coppersmith relationship (lower line), our preferred relationship (middle line) and a third relationship (upper line) defined by $k=4.3$. Although there are some data above the highest line, none are in error by more than 0.2 magnitude units, or comfortably within an assumed random variation of magnitude of 0.12 (standard deviation).

Lastly, although we have no a priori means for assigning weights to the three alternative relations, we assign branch weights of $0.2,0.6$, and 0.2 , in accordance with similar decisions made elsewhere in the calculation sequence and corresponding roughly to a confidence interval of one standard deviation. 


\section{SELECTED REFERENCES}

Andrews, D.J. and Schwerer, E., unpublished manuscript, Probability of rupture of multiple fault segments.

Arnodottir, T., Segall, P., Matthews, M., 1992, Resolving the discrepancy between geodetic and seismic fault models for the 1989 Loma Prieta, California, earthquake: Seismological Society of America Bulletin, v. 82, p. 2248-2255.

Bakun, W., 1999, Seismic Activity of the San Francisco Bay Region, Bulletin Seismological Society of America, v. 89, p. $764-784$.

Beanland, S., and Clark, M. M., 1994, The Owens Valley fault zone and surface rupture in the Inyo County, California earthquake of 1872: U. S. Geological Survey Bulletin 1982, 29 p.

Borchardt, G., 1999, Holocene slip rate of the Concord fault at Galindo Creek in Concord, California: U.S. Geological Survey, National Earthquake Hazards Reduction Program, Annual Project Summaries, v. 40, Award \# 1434-HQ-97GR-03102, 5 p.

Bufe, C.G., and Varnes, D. J., 1993, Predictive modelling of the seismic cycle of the greater San Francisco Bay region: Journal of Geophysical Research, v. 98, p. 9871-9883.

Cox, D. R. and P. A. Lewis, 1966, The Statistical Analysis of a Series of Events: Methuen, London.

Dolan, J. F. et al., 1995, Prospects for larger or more frequent earthquakes in the Los Angeles metropolitan region: Science, v. 267, p. 199-205.

Ellsworth, W.L., M.V. Matthews, R.M. Nadeau, S.P. Nishenko, P.A. Reasenberg and R.W. Simpson, 1998, A physically-based earthquake recurrence model for estimation of long-term earthquake probabilities, Proceedings of the Second Joint Meeting of the UJNR Panel on Earthquake Research, 135-149.

Frankel, A., Mueller, C., Barnhard, T., Perkins, D., Leyendecker, E.V., Dickman, N. Hanson, S., and Hopper, M., 1996, National Seismic Hazard Maps: Documentation June 1996: U.S. Geological Survey Open-File Report 96$532,44 \mathrm{p}$.

Freymueller, J., King, N. E., Segall, P., 1994, The co-seismic slip distribution of the Landers earthquake: Seismological Society of America Bulletin, v. 84, p. 646-659.

Galehouse, J. S., 1997, Effect of the Loma Prieta earthquake on fault creep rates in the San Francisco Bay region, U.S. Geological Survey Profess. Pap.1550D, 193-207.

Hall, N. T., Wright, R. H., and Clahan, K. B., 1999 in press, Paleoseismic studies of the San Francisco peninsula segment of the San Andreas fault zone near Woodside, California: Journal of Geophysical Research. 
Harris, R.A. and Simpson, R.W., 1998, Suppression of large earthquakes by stress shadows: a comparison of Coulomb and rate-and-state failure: Journal of Geophysical Research, v. 103, p. 24,439-24,451.

Hayward Fault Paleoearthquake Group, 1999, Timing of paleoearthquakes on the northern Hayward fault—preliminary evidence in El Cerrito, California, U.S. Geological Survey Open-File Report 99-318, 34 p.

Hudnut, K.W., et al., 1994, Co-seismic displacements of the 1992 Landers earthquake sequence: Seismological Society of America Bulletin, v. 84, p. 625-645.

Jaume, S.C., and Sykes, L.R., 1996, Evolution of moderate seismicity in the San Francisco Bay region, 1850 to 1993 : Seismicity changes related to the occurrence of large and great earthquakes: Journal of Geophysical Research, v. 101, p. 765-789.

Kanamori, H., and C. R. Allen, 1986, Earthquake repeat time and average stress drop: in Das, S., J. Boatwright, and C. Scholz, eds., Earthquake source mechanics, American Geophysical Union Geophysical Monograph, 37, p. $227-235$.

Kelson, K. I., Simpson, G. D., Lettis, W. R., and Haraden, C. C., 1996, Holocene slip rate and recurrence of the northern Calaveras fault at Leyden Creek, eastern San Francisco Bay region: Journal of Geophysical Research, v. 101, no. B3, p. 5961-5975.

Kelson, K. I., et al., 1998, Late Holocene slip rate and amounts of coseismic rupture along the central Calaveras fault, San Francisco Bay area, California: Final Technical Report submitted to the U.S. Geological Survey National Earthquake Hazard Reduction Program, Award Number 1434-HQ-97-GR-03151, p. 26 pp.

King, N.E., and Thatcher, W., 1998, The coseismic slip distributions of the 1940 and 1979 Imperial Valley, California, earthquakes and their implications: Journal of Geophysical Research, v. 103, p. 18,069-18,086.

Lienkaemper, J. J., and Borchardt, G., 1996, Holocene slip rate of the Hayward fault at Union City, California: Journal of Geophysical Research, v. 101, no. B3, p. 6099-6108.

Lindh, A.G., 1983, Preliminary assessment of long-term probabilities for large earthquakes along selected segments of the San Andreas fault system in California: U.S. Geological Survey Open-File Report 83-63, p. 1-15.

Lisowski, M., Prescott, W.H., Savage, J.C., and Johnston, M.J., 1990, Geodetic estimate of coseismic slip during the 1989 Loma Prieta, California, earthquake: Geophysical Research Letters, v. 17, p. 1437-1440.

Matthews, M.V., 1999, A stochastic model for recurrent earthquakes, unpublished manuscript.

Michael, A. J., Ross, S. L., Schwartz, D. P., Hendley, J. W., II, and Stauffer, P. H., 1999, Major quake likely to strike between 2000 and 2030_-Understanding Earthquake Hazards in the San Francisco Bay Region, U. S. Geological Survey Fact Sheet 152-99, 4 p. 
Nishenko, S.P. and R.A. Buland, 1987, A generic recurrence interval distribution for earthquake forecasting: Bulletin Seismological Society of America, v. 77, p. 1382-1399.

Oppenheimer, D. H., Bakun, W. H., and Lindh, A. G., 1990, Slip partitioning of the Calaveras fault, California, and prospects for future earthquakes: Journal of Geophysical Research, v. 95, no. B6, p. 8483-8498.

Petersen, M.D., Bryant, W.A., Cramer, C.H., Cao, T., Reichle, M.S., Frankel, A.D., Lienkaemper, J.J., McCrory, P.A., and Schwartz, D.P, 1996, Probabilistic seismic hazard assessment for the State of California: California Division of Mines and Geology Open-File Report 96-08 published jointly as U.S. Geological Survey Open-File Report 96-706, 59 p.

Prescott, W. H., and M. Lisowski, 1983, Strain accumulation along the San Andreas fault system east of San Francisco Bay, California: Tectonophysics, v. 97, p. 41-56.

Reasenberg, P.A., and Jones, L.M., 1989, Earthquake hazard after a mainshock in California: Science, v. 243, p. 11731176.

Reasenberg, P.A., and Jones, L.M., 1994, Earthquake aftershocks--Update: Science, v. 265,. p. 1251-1252.

Reid, H. F., 1910, The Mechanics of the Earthquake, The California earthquake of April 18, 1906: Report of the State Earthquake Investigation Commission (Volume II): Carnegie Institution of Washington Publication No. 87, 192 p.

Sammis, C.G., Sornette, D., and Saleur, H., 1996, Complexity and earthquake forecasting, in Rundle, J.B., Klein, W., and Turcotte, D.L., eds., Reduction and Predictability of Natural Disasters, SFI Studies in the Sciences of Complexity, v. XXV: Addison-Wesley, Reading, Mass., pp. 143-156.

Schwartz, D. P., Pantosti, D., Hecker, S., Okamura, K., Budding, K. E., and Powers, T., 1993, Late Holocene behavior and seismogenic potential of the Rodgers Creek fault zone, Sonoma County, California: California Division of Mines and Geology Special Publication, v. 113, p. 393-398.

Schwartz, D. P., Pantosti, D., Okumura, K., Powers, T., and Hamilton, J., 1998, Paleoseismic investigations in the Santa Cruz Mountains: Implications for the recurrence of large magnitude earthquakes on the San Andreas Fault: Journal of Geophysical Research, v. 103, p. 17,985-18,001.

Shimazaki, K., and Nakata, T., 1980, Time-predictable recurrence model for large earthquakes: Geophysical Research Letters, v. 7, p. 279-282.

Sieh, K.E., 1978, Slip along the San Andreas fault associated with the great 1857 earthquake: Seismological Society of America Bulletin, v. 68, p. 1421-1448. 
Simpson, G. D., Thompson, S. C., Noller, J. S., Lettis, W. R., Williams, 1998, The northern San Gregorio fault zone: Evidence for the timing of late Holocene earthquakes near Seal Cove, California: Bulletin Seismological Society of America, v. 87, no. 5, p. 1158-1170.

Sommerville, P., Irikura, K. Graves, R. Sawada, S. Wald, D. Abrahamson, N Iwasaki, Y. Kagawa, T. Smith, N. and Kowada, A., 1999, Characterizing crustal earthquake slip models for prediction of strong ground motion: Seismological Research Letters, v. 70, no. 1, p. 59-80.

Stein, R.S., Barka, A.A., and Dieterich, J.H., 1997, Progressive failure on the North Anatolian fault since 1939 by earthquake stress triggering: Geophysical Journal International, v. 128, p. 594-604.

Stein, R.S., and Hanks, T.C., 1998, M>=6 earthquakes in southern California during the twentieth century: no evidence for a seismicity or moment deficit: Seismological Society of America Bulletin, v. 88, p. 635-652.

Sykes, L.R., and Nishenko, S.P., 1984, Probabilities of occurrence of large plate rupturing earthquakes for the San Andreas, San Jacinto, and Imperial faults, California: Journal of Geophysical Research, v. 89, p. 5905-5927.

Thatcher, W., Marshall, G., Lisowski, M., 1997, Resolution of fault slip along the 470-km-long rupture of the great 1906 San Francisco earthquake and its implications: Journal of Geophysical Research v. 102, p.5353-5367.

Toda, S., Stein, R. S., Reasenberg, P. A., Dieterich, J. H., and Yoshida, A., 1998, Stress transferred by the 1995 $\mathrm{Mw}=6.9$ Kobe, Japan, shock: Effect on aftershocks and future earthquake probabilities: Journal of Geophysical Research, v. 103, p. 24,543-24,565.

Toppozada, T. R., and Borchardt, G., 1998, Re-evaluation of the 1836 "Hayward Fault" earthquake and the 1838 San Andreas Fault earthquake: Bulletin Seismological Society of America, v. 88, 140-159.

Unruh, J. R., and Sawyer, T. L., 1998, Paleoseismic investigation of the northern Greenville fault, Eastern San Francisco Bay area, California: Final Technical Report, U.S. Geological Survey, Award 1434-HQ-97-GR-03146, 34 p.

Wakabayashi, J. and J. Hengesh, 1995, Distribution of late Cenozoic displacement on the San Andreas fault system, northern California: Special Publication Pacific Section, Society of Economic Paleontologists and Mineralogists, v. 76, p. 19-29.

Wald, D. J., Kanamori, H., Helmberger, D. V., and Heaton, T. H., 1993, Source study of the 1906 San Francisco earthquake: Bulletin Seismological Society of America, v. 83, no. 4, p. 981-1019.

Ward, S., 1999, San Francisco Bay Area earthquake simulations: A step towards a standard physical earthquake model: Bulletin Seismological Society of America, in press. 
Weber, G. E., 1980, Recurrence intervals and recency of faulting along the San Gregorio fault zone, San Mateo County, California [Ph.D. dissertation]: University of California, Santa Cruz, 204 p.

Weber, G. E., and Nolan, J. M., 1995, Determination of late Pleistocene-Holocene slip rates along the San Gregorio fault zone, San Mateo County, California: U.S. Geological Survey Open-File Report 95-210, p. 805-807.

Wells, D. L., and Coppersmith, K. J., 1994, New empirical relationships among magnitude, rupture length, rupture width, rupture area, and surface displacement: Seismological Society of America Bulletin, v. 84, no. 4, p. 974-1002.

Wesson, R. L., W.H. Bakun and Perkins, D.A.,. Manuscript in preparation, Estimating the frequency-magnitude relation and probabilities for the background earthquake from historic seismicity data.

Williams, P. L., 1993, Geologic record of southern Hayward fault earthquakes: California Division of Mines and Geology Special Publication, v. 113, p. 171-179.

Working Group on California Earthquake Probabilities, 1988, Probabilities of large earthquakes occurring in California on the San Andreas fault, U.S. Geological Survey Open-File Report 88-398.

Working Group on California Earthquake Probabilities, 1990, Probabilities of large earthquakes in the San Francisco Bay Region, California: U.S. Geological Survey Circular 1053, 51 pp.

Working Group on California Earthquake Probabilities, 1995, Seismic hazards in southern California: probable earthquakes, 1994-2024, Bulletin Seismological Society of America, v. 85, p. 379-439.

Working Group on Northern California Earthquake Potential, 1996, Database of potential sources for earthquakes larger than magnitude 6 in northern California, U.S. Geological Survey Open-File Rep. 96-705, 53 p. Browse and download at: http://quake.wr.usgs.gov/hazprep/NCEP/

Wright, R. H., Hamilton, D. H., Hunt, T. D., Traubenik, M. L., and Shlemon, R. J., 1982, Character and activity of the Greenville structural trend: California Division of Mines and Geology Special Publication, v. 62, p. 187-196.

Yu, E. and Segall, P., 1996, Slip in the 1868 Hayward earthquake from the analysis of historical triangulation data: Journal of Geophysical Research, v. 101, p. 16101-16118.

Zoback, M. L., Jachens, R. C., and Olson, J. A., 1999, Abrupt along-strike change in tectonic style: San Andreas fault zone, San Francisco Peninsula: Journal of Geophysical Research, v. 104, p. 10719-10742. 


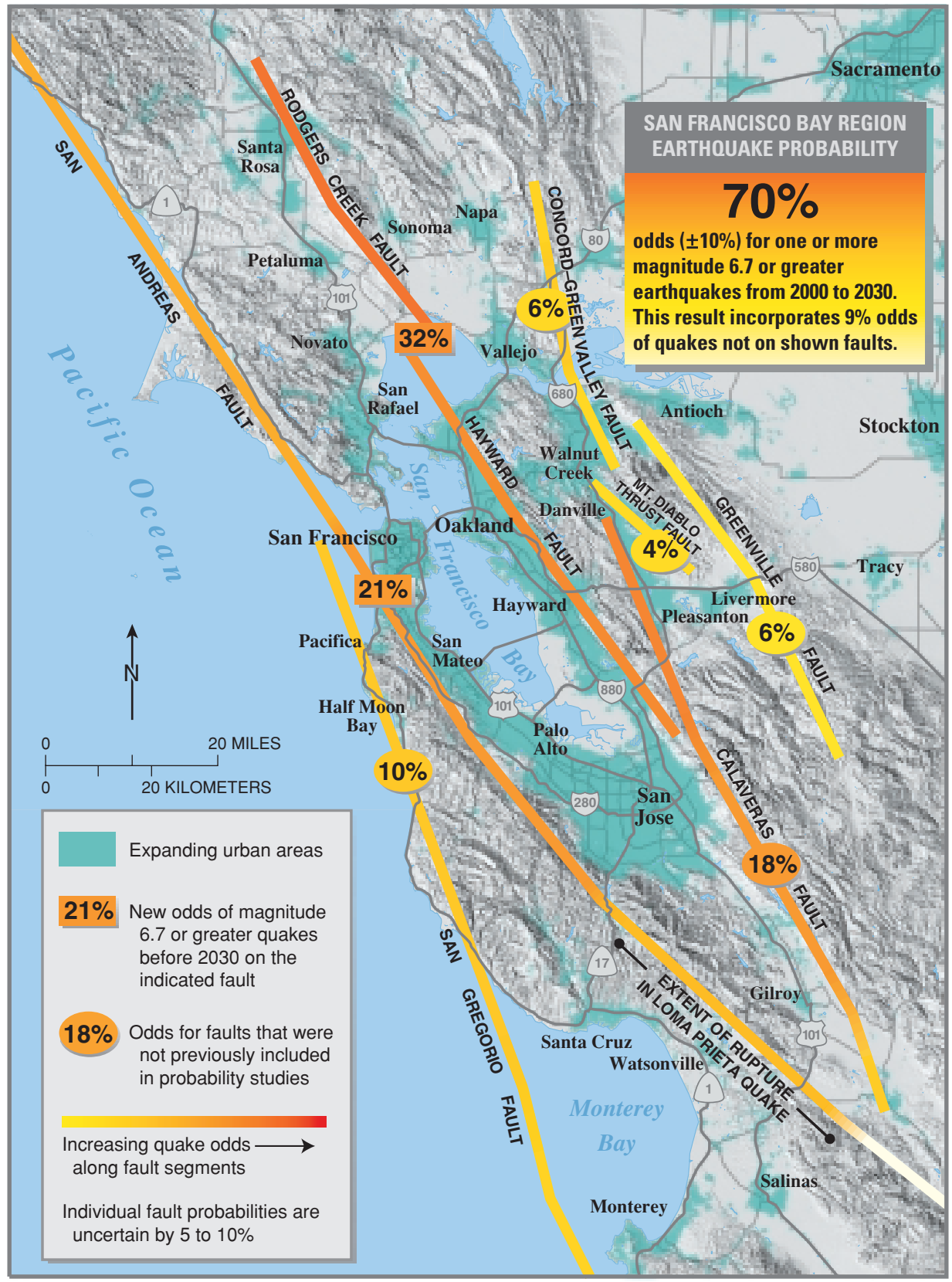

Figure 1. The threat of earthquakes extends across the entire San Francisco Bay region, and a major quake is likely before 2030. Knowing this will help people make informed decisions as they continue to prepare for future quakes. 


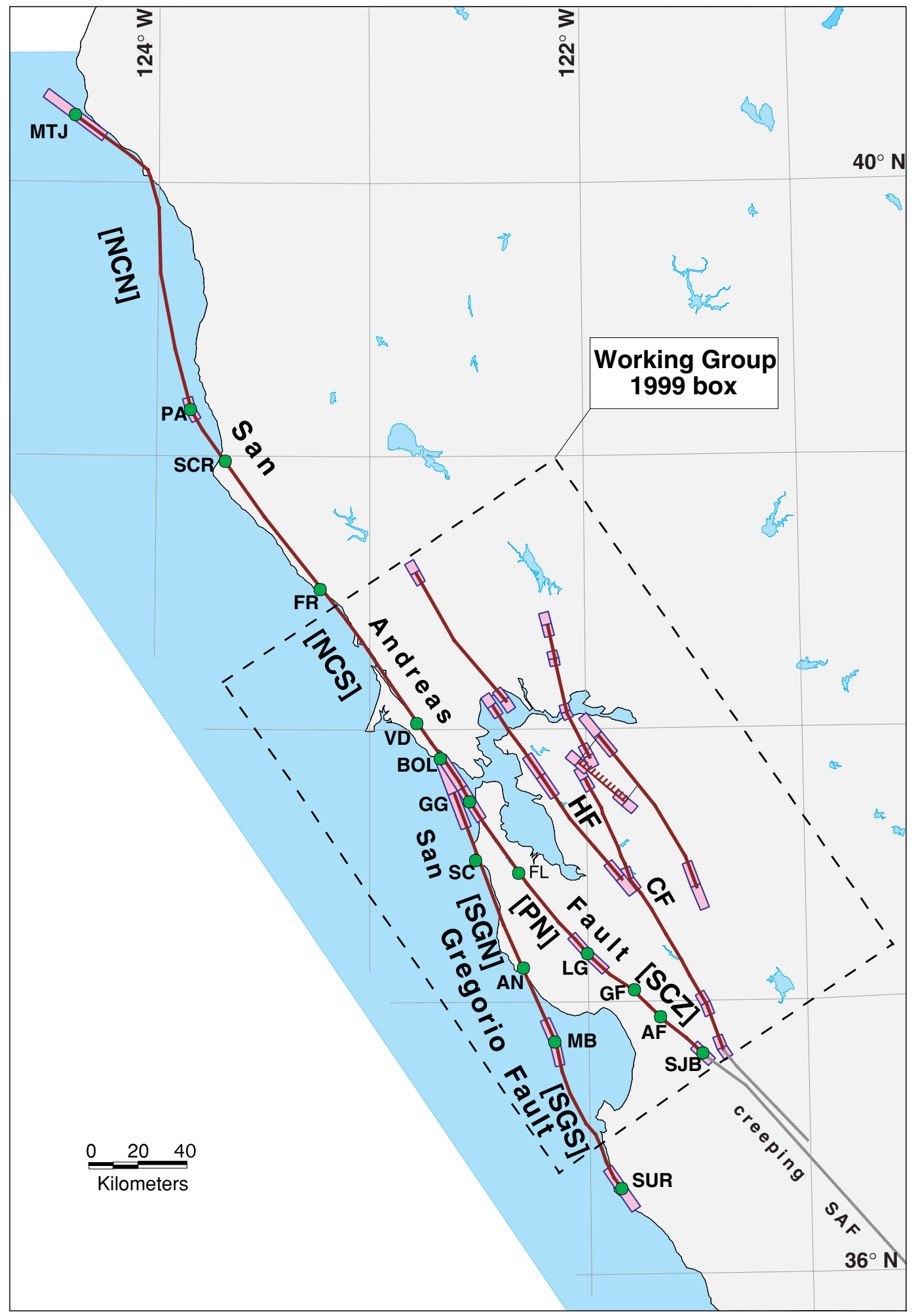

Figure 2. A, Dashed rectangle (Working Group 1999 box) shows the region included for calculation of earthquake probability and seismic moment. Bold solid lines indicate major faults for which probabilities were calculated. For San Andreas and San Gregorio Fault subsystem, this map shows major fault segments in square brackets (e.g., [NCN], [NCS], etc.; see table 2 for segment names and discussion.) Length of shaded rectangles indicates approximate uncertainty in the position of each segment boundary. Circles show locations from which data have been obtained on the slip or past earthquake behavior of those faults. Localities (circles): AF, Arano Flat; AN, Ano Nuevo; BOL, Bolinas, FL, Filoli; FR, Fort Ross; GF, Grizzly Flat; GG, Golden Gate stepover zone in SAF and SGF; LG, Los Gatos bend in SAF; MB, Monterey bend in SGF; MTJ, Mendocino triple junction; PA, Point Arena; SC, Seal Cove; SCR, Scaramella Ranch; SJB, San Juan Bautista; SUR, Point Sur; VD, Vedanta. For more on Hayward (HF) and Calaveras (CF), and other fault subsystems see text, table 2, and figures in Section 3. 


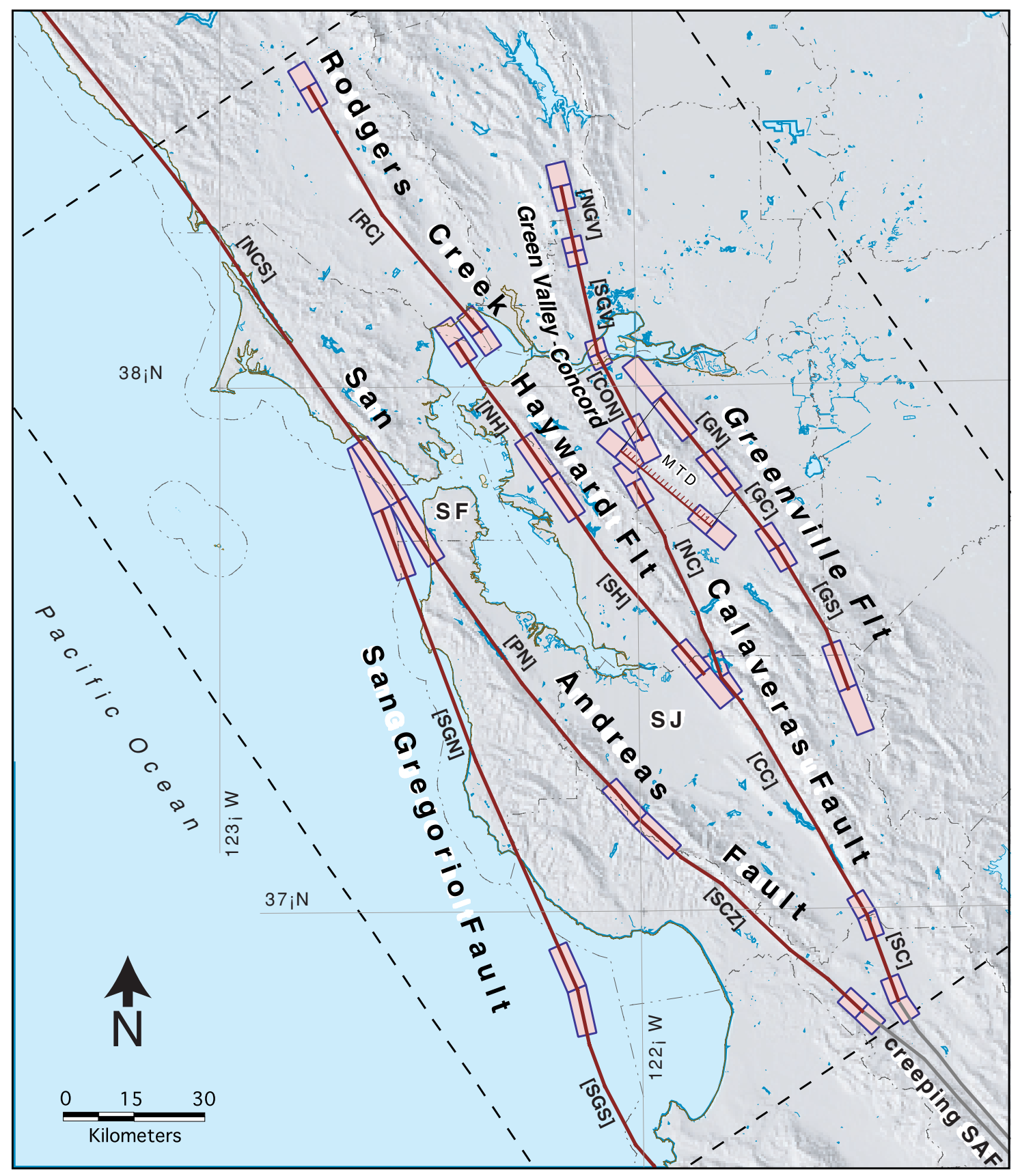

Figure 2. $B$, Enlarged view of Working Group 99 box. 


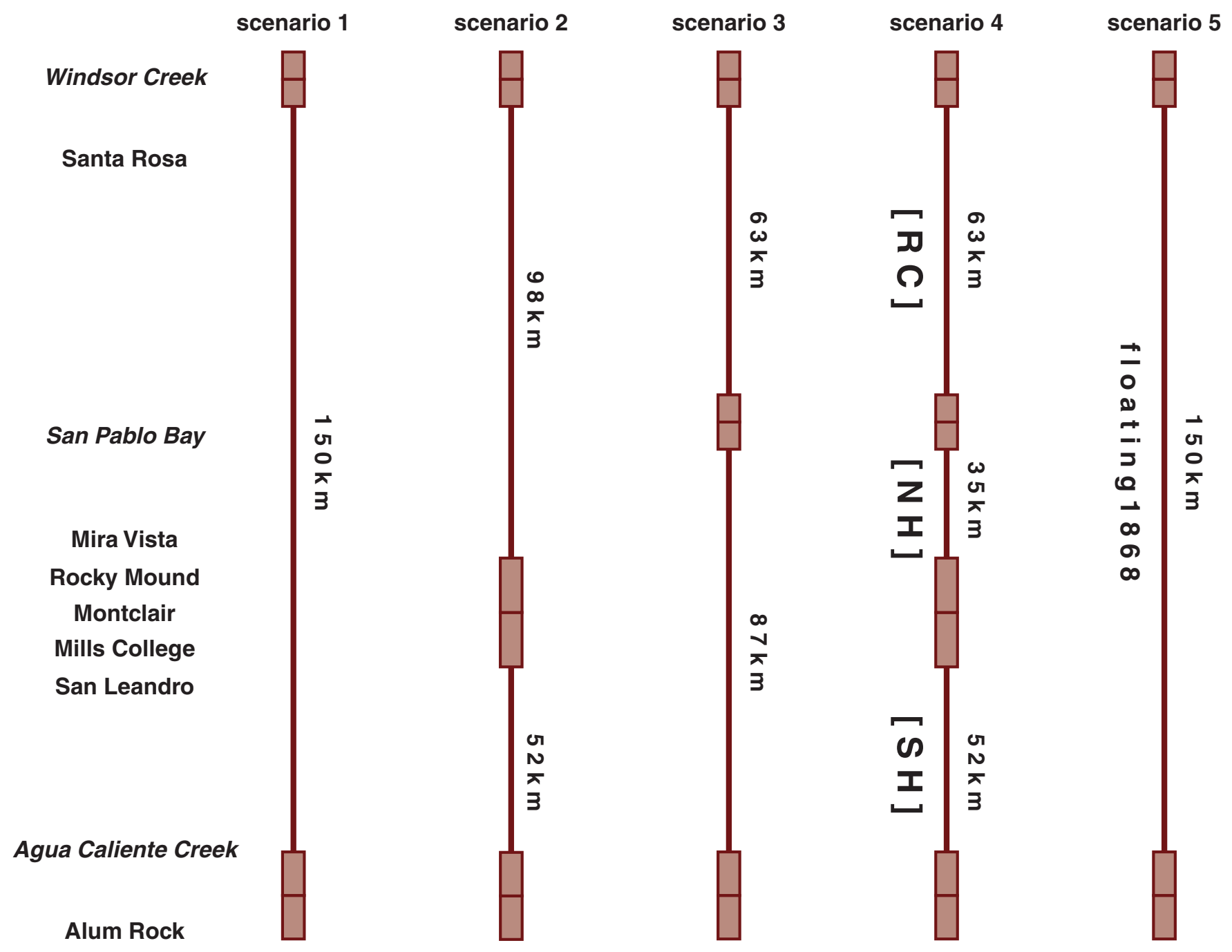




\section{Regional Magnitude-Frequency Relation}

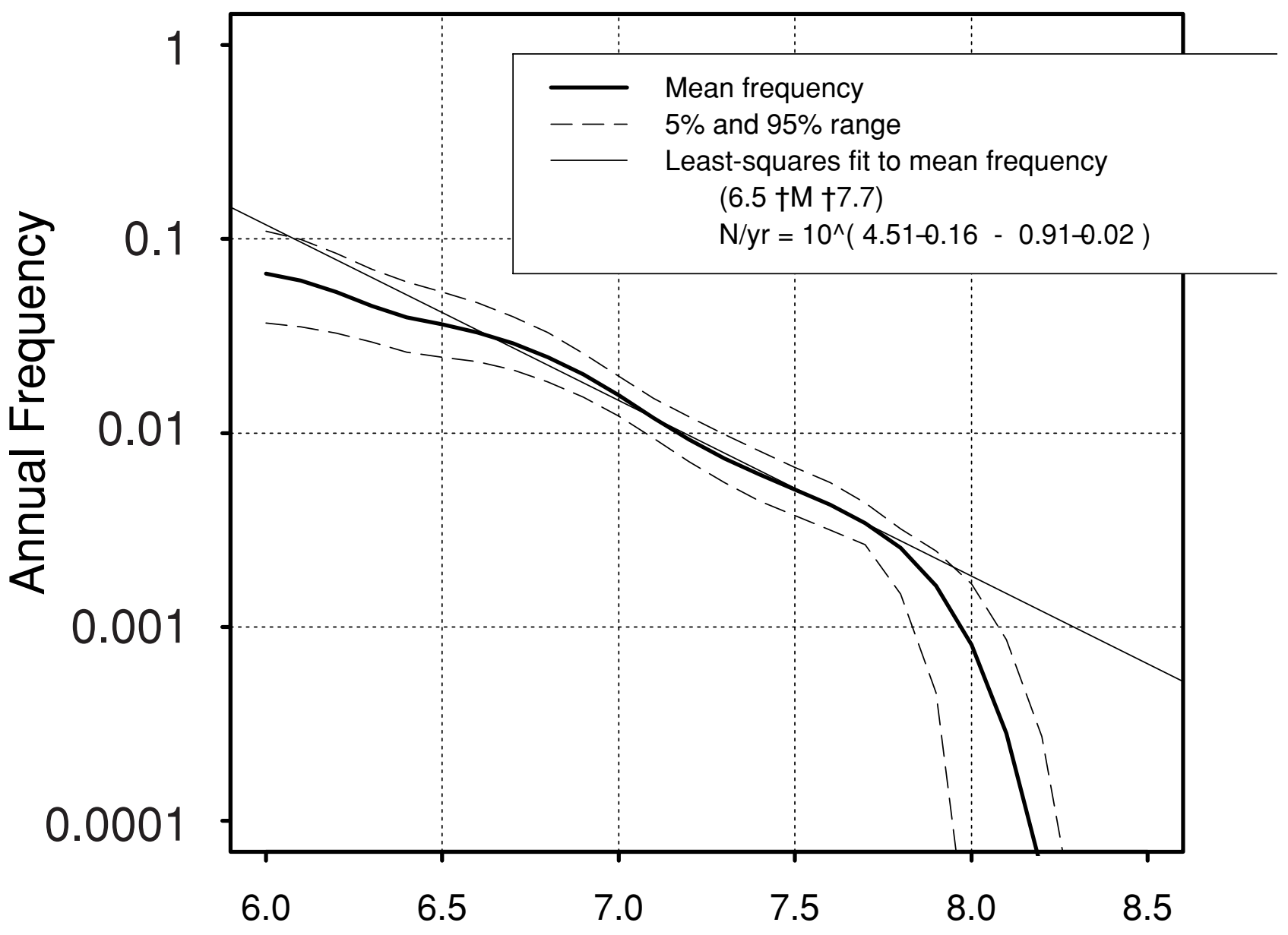

\section{Magnitude}

Figure 4. Cumulative rate for all characteristic rupture sources in the calculation sequence is shown as heavy solid line. The mean rate for each characteristic rupture source was used without sampling. The distribution of magnitudes obtained at the branch tips of the calculation sequence (heavy dashed line) shows the smoothing effect of sampling over parametric distributions in the calculation. A Gutenberg-Richter (G-R) model (light broken line) fit by least-squares over the range $6.5 \leq \mathrm{M} \leq 7.7$ to the cumulative rates obtained at the branch tips has b-value of $0.91 \pm 0.02$ (one standard deviation) and $\mathrm{a}=4.56 \pm 0.15$. Two relations for the cumulative rate of "background" earthquakes (shown by light solid lines) are derived from the two G-R models: $\mathrm{a}$ (incremental) $=3.129, \mathrm{~b}=0.8624$; and $\mathrm{a}$ (incremental) $=2.989, \mathrm{~b}=0.8320$. 


\section{$M>=6.7$ Regional Rates - Summary}

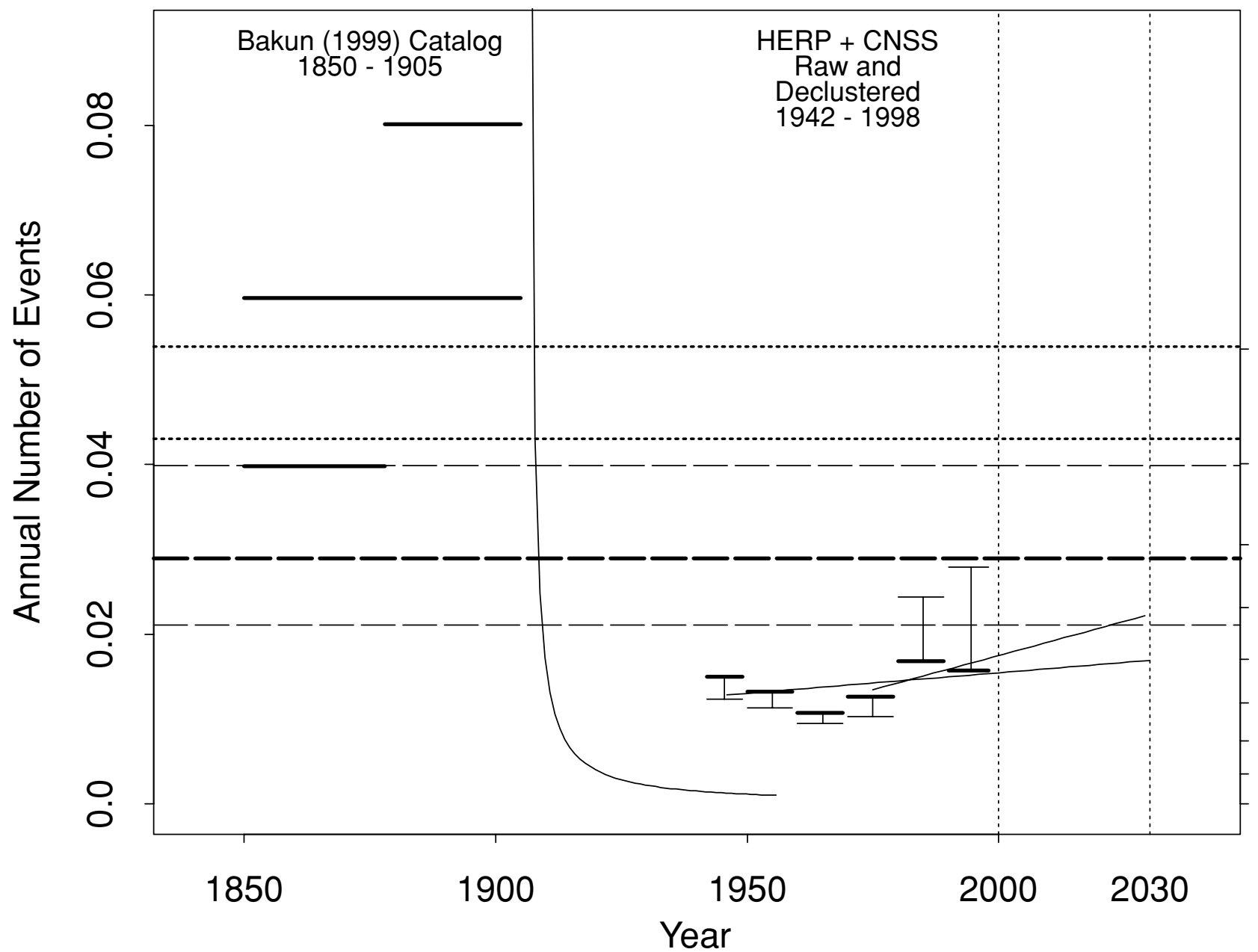

Figure 5. Summary of regional rates of $M \geq 6.7$ earthquakes inferred from Gutenberg-Richter (G-R) models. The height of each solid horizontal line represents an average rate extrapolated from a G-R model, while its width indicates the time period of the data used. For the 20th century data, two rate estimates for each decadal period — one made with the full catalog (light lines) and one with a declustered catalog (heavy lines)) — provide bounds on the estimated contemporary rates, and hence are shown connected with vertical lines. Sloping straight lines are least-squares fits to the rates estimated with the declustered catalog, and are considered lower bounds on the rate trend. The more shallowly sloped line is the fit to all six decades, while the more steeply sloped line is the fit through the last three decades only. . Curved line represents the instantaneous rate of $M \geq 6.7$ earthquakes expected in a generic California aftershock sequence (Reasenberg and Jones, 1989) following a M=7.8 mainshock in 1906. Heavy dashed line is the mean regional long-term rate of earthquakes on all rupture sources in the calculation sequence, including the "background" source. Light dashed lines are the corresponding 5th and 95th percentile values in the calculation sequence for this quantity. Upper and lower heavy dotted horizontal lines are long-term regional rates estimated, respectively, by Andrews and Schwerer (unpublished manuscript), based on a regional segmentation utilizing Working Group On Northern California Earthquake Potential 1996 fault segments, and Ward (in press), based on a simulated physical earthquake model. 


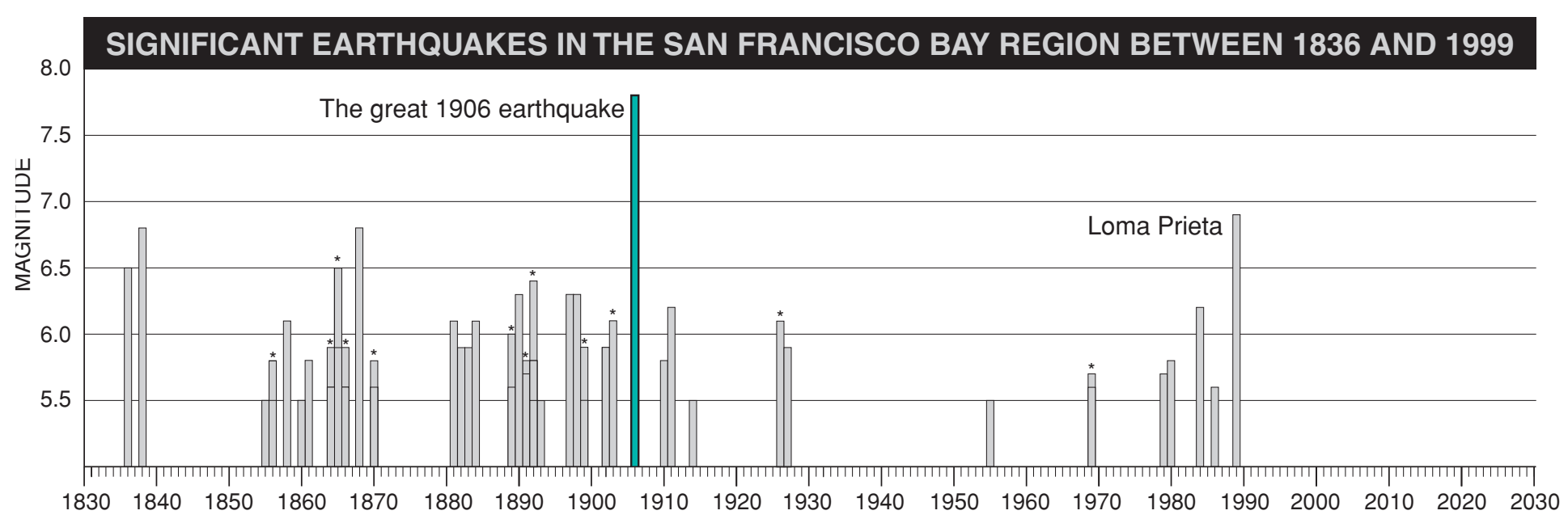

Figure 6. Time sequence of earthquakes $M>=5.5$ in the SFBR since the early 19th century, from the catalog of Bakun (1999) The catalog is believed to be complete for such magnitude earthquakes since 1850. A high rate of earthquake activity in the late 1800's was followed by relatively little activity after 1906. Asterisk indicates more than one earthquake occurred that year. 


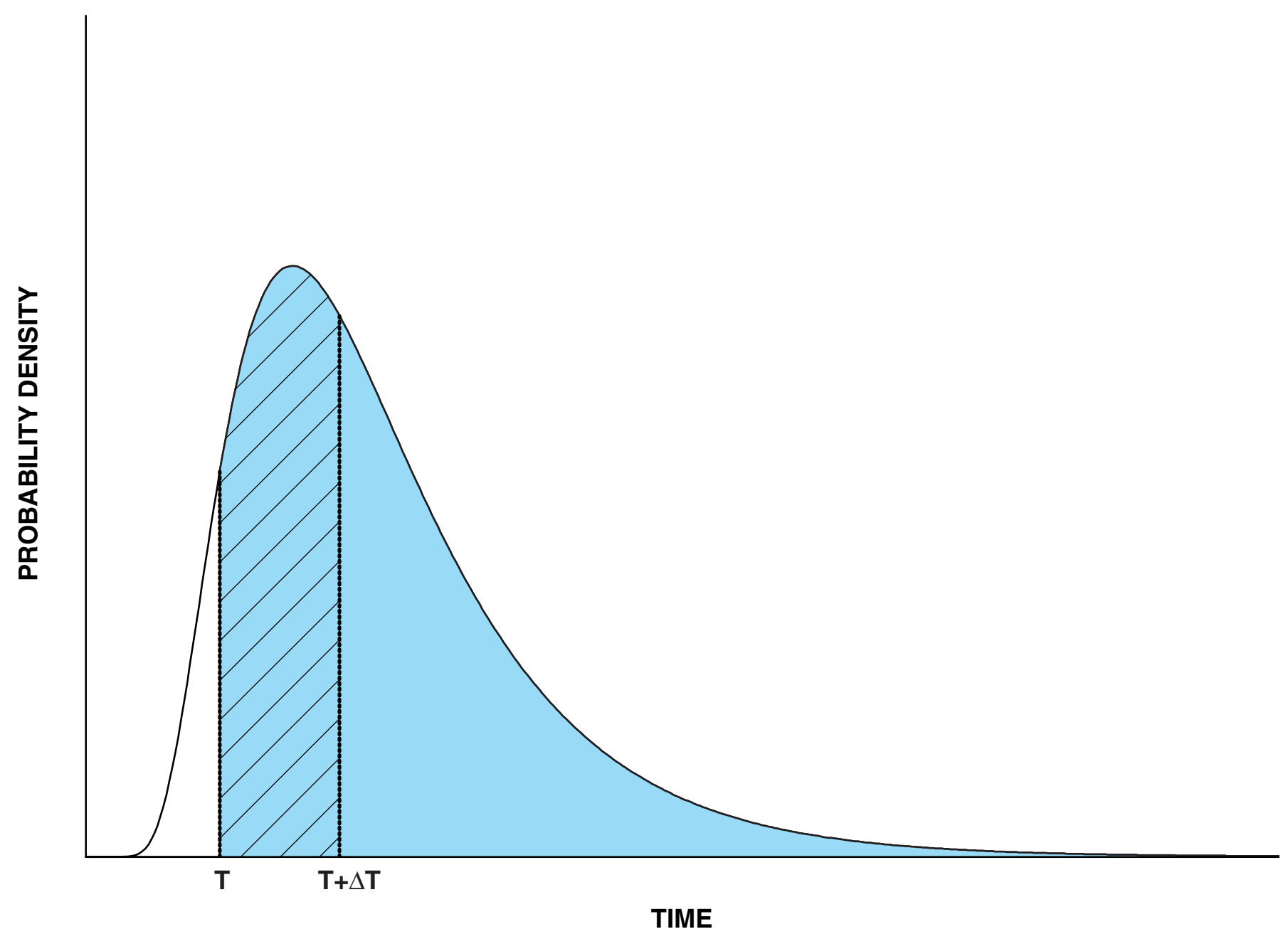

Figure 7. Diagram illustrating the calculation of conditional probability from a probability density function. The time interval of interest (exposure time) is striped. The survivor function is equal to the shaded area. The conditional probability is the ratio of the two areas. 


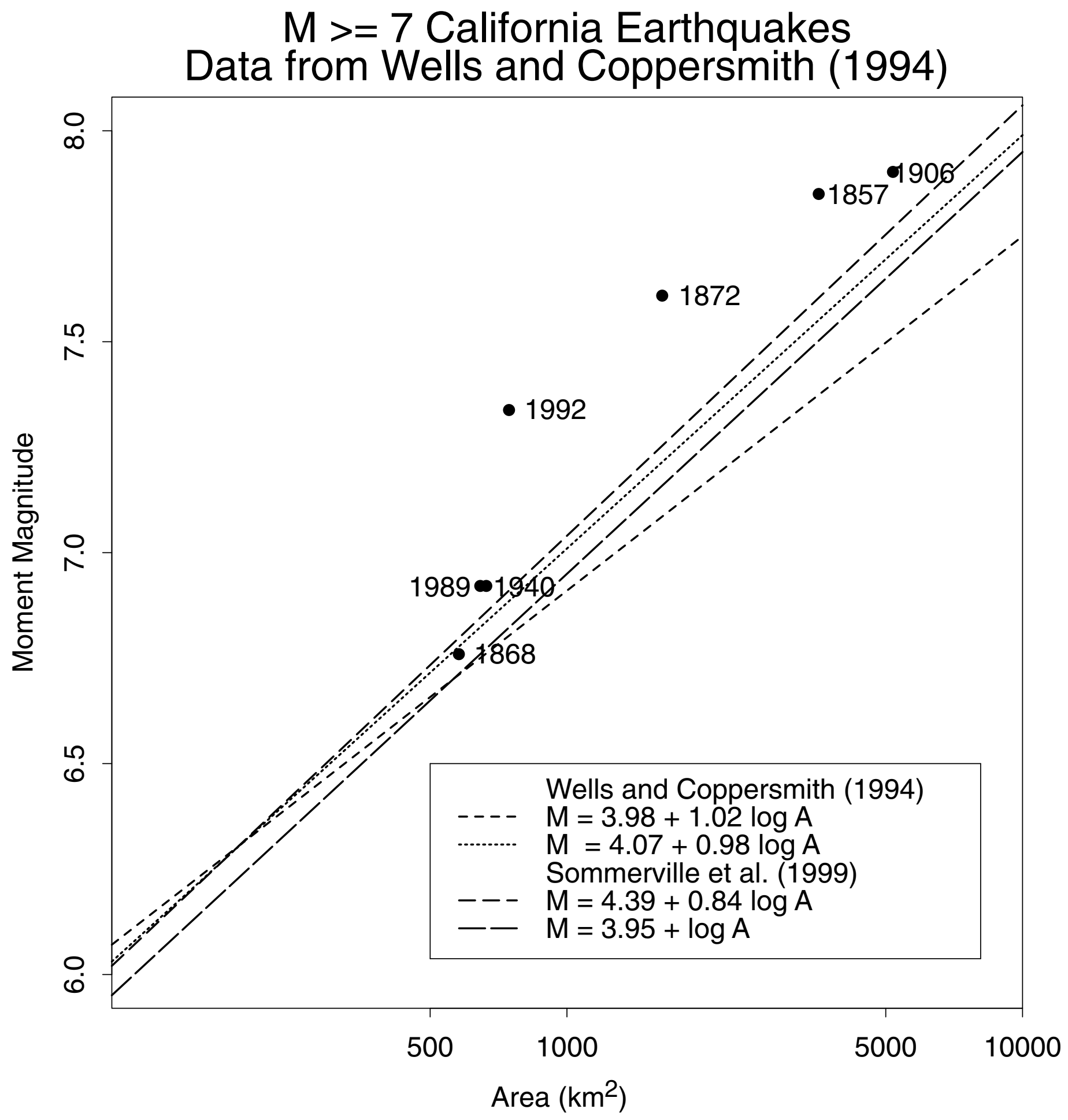

Figure C1. Moment magnitudes, M, and rupture areas, $A$, for large California earthquakes analyzed by Wells and Coppersmith (1994), with various fits to the data as explained in the text. 


\section{7 California Earthquakes}

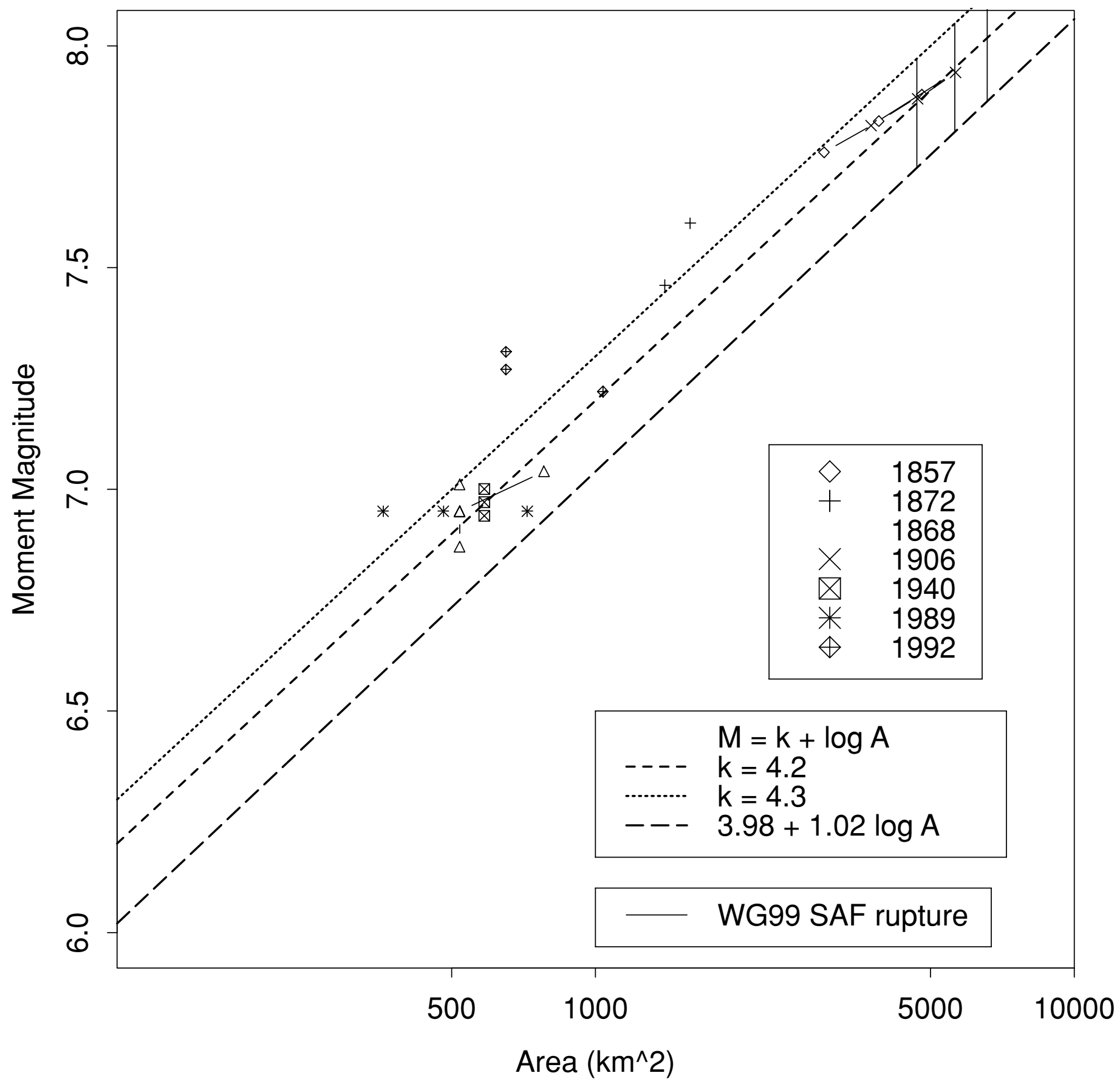

Figure C2. Moment magnitudes, $\mathbf{M}$, and rupture areas, $A$, for large California earthquakes. Events are identified by year of occurrence. Three model proposed $\mathbf{M}-A$ relations are shown. Solid line is the Wells and Coppersmith (1994) relation, middle line is the preferred relation for this report, and top line is upper bound relation. 
Table 1. Probability of At Least One $\boldsymbol{M} \geq 6.7$ Earthquake Before 2030

Fault system Probability

\begin{tabular}{lc}
\hline \hline San Gregorio & 0.10 \\
San Andreas & 0.21 \\
Hayward-Rodgers Creek & 0.32 \\
Calaveras & 0.18 \\
Concord-Green Valley & 0.06 \\
Greenville & 0.06 \\
Mount Diablo & 0.04 \\
Background & 0.09 \\
\hline Regional aggregate & 0.70 \\
\hline
\end{tabular}




\section{Table 2. Fault Segment Parameters}

[The Mount Diablo blind thrust is modeled as an inclined trapezoid, top edge at $8 \mathrm{~km}$ depth and deepest corner at $18.8 \mathrm{~km}$ depth (Fig. 2b). Three options are modeled for the most recent recent earthquake on the Northern Calaveras Fault: pre-1776, 1897, and 1984 , with weights $0.2,0.5$, and 0.3 , respectively.]

\begin{tabular}{|c|c|c|c|c|c|c|c|c|c|c|c|}
\hline \multicolumn{2}{|l|}{ Fault Segment } & \multicolumn{2}{|c|}{ Length (km) } & \multicolumn{2}{|c|}{$\begin{array}{c}\text { Seismic } \\
\text { Width (km) }\end{array}$} & \multicolumn{2}{|c|}{$\begin{array}{l}\text { Slip Rate } \\
(\mathrm{mm} / \mathrm{yr})\end{array}$} & \multicolumn{3}{|c|}{ Seismic Slip Factor } & \multirow[t]{2}{*}{$\begin{array}{c}\text { Most recent } \\
\text { event }\end{array}$} \\
\hline System & Code & Mean & $\pm 2 \sigma$ & Mean & $\pm 2 \sigma$ & Mean & $\pm 2 \sigma$ & Mean & $\pm 2 \sigma$ & wts. & \\
\hline San Gregorio North & SGN & 109 & \pm 13 & 13 & \pm 2 & 7 & \pm 3 & 1 & - & - & pre 1776 \\
\hline San Gregorio South & SGS & 66 & \pm 10 & 12 & \pm 2 & 3 & \pm 2 & 1 & - & - & pre 1776 \\
\hline SAF - North Coast North & NCN & 137 & \pm 11 & 11 & \pm 2 & 24 & \pm 3 & 1 & - & - & 1906 \\
\hline SAF - North Coast South & NCS & 190 & \pm 11 & 11 & \pm 2 & 24 & \pm 3 & 1 & - & - & 1906 \\
\hline SAF - Peninsula & $\mathrm{PN}$ & 85 & \pm 13 & 13 & \pm 2 & 17 & \pm 4 & 1 & - & - & 1906 \\
\hline SAF - Santa Cruz Mtns & SCZ & 62 & \pm 8 & 15 & \pm 2 & 17 & \pm 4 & 1 & - & - & 1906 \\
\hline Rodgers Creek & $\mathrm{RC}$ & 63 & \pm 5 & 12 & \pm 2 & 9 & \pm 2 & 1 & - & - & $1670-1776$ \\
\hline Northern Hayward & $\mathrm{NH}$ & 35 & \pm 8 & 12 & \pm 2 & 9 & \pm 2 & 0.6 & \pm 0.3 & $.2 / .4 / .4$ & $1640-1776$ \\
\hline Southern Hayward & $\mathrm{SH}$ & 52 & \pm 9 & 12 & \pm 2 & 9 & \pm 2 & 0.8 & \pm 0.2 & $.1 / .8 / .1$ & 1868 \\
\hline Northern Calaveras & NC & 45 & \pm 5 & 13 & \pm 2 & 6 & \pm 2 & 0.9 & \pm 0.1 & $.2 / .6 / .2$ & see notes \\
\hline Central Calaveras & $\infty$ & 59 & \pm 5 & 11 & \pm 2 & 15 & \pm 3 & 0.4 & \pm 0.3 & $.1 / .8 / .1$ & pre 1776 \\
\hline Southern Calaveras & $\mathrm{SC}$ & 19 & \pm 5 & 11 & \pm 2 & 15 & \pm 3 & 0.4 & \pm 0.3 & $.1 / .8 / .1$ & pre 1776 \\
\hline Northern Green Valley & NGV & 14 & \pm 4 & 14 & \pm 2 & 5 & \pm 3 & 0.5 & \pm 0.5 & thirds & pre 1776 \\
\hline Southern Green Valley & SGV & 22 & \pm 3 & 14 & \pm 2 & 5 & \pm 3 & 0.5 & \pm 0.5 & thirds & pre 1776 \\
\hline Concord & CON & 20 & \pm 4 & 16 & \pm 2 & 4 & \pm 2 & 0.5 & \pm 0.5 & thirds & pre 1776 \\
\hline Northern Greenville & NG & 20 & \pm 8 & 15 & \pm 3 & 2 & \pm 1 & 1 & - & - & pre 1776 \\
\hline Central Greenville & CG & 20 & \pm 5 & 15 & \pm 3 & 2 & \pm 1 & 1 & - & - & pre 1776 \\
\hline Southern Greenville & $S G$ & 33 & \pm 8 & 15 & \pm 3 & 2 & \pm 1 & 1 & - & - & pre 1776 \\
\hline Mount Diablo thrust & MTD & 25 & \pm 5 & 14.2 & \pm 2 & 3 & \pm 2 & 1 & - & - & pre 1776 \\
\hline
\end{tabular}


Table 3. Magnitudes and long-term earthquake rates on rupture sources

[See table 2 for explanation of segment codes]

Fault system

Rupture source

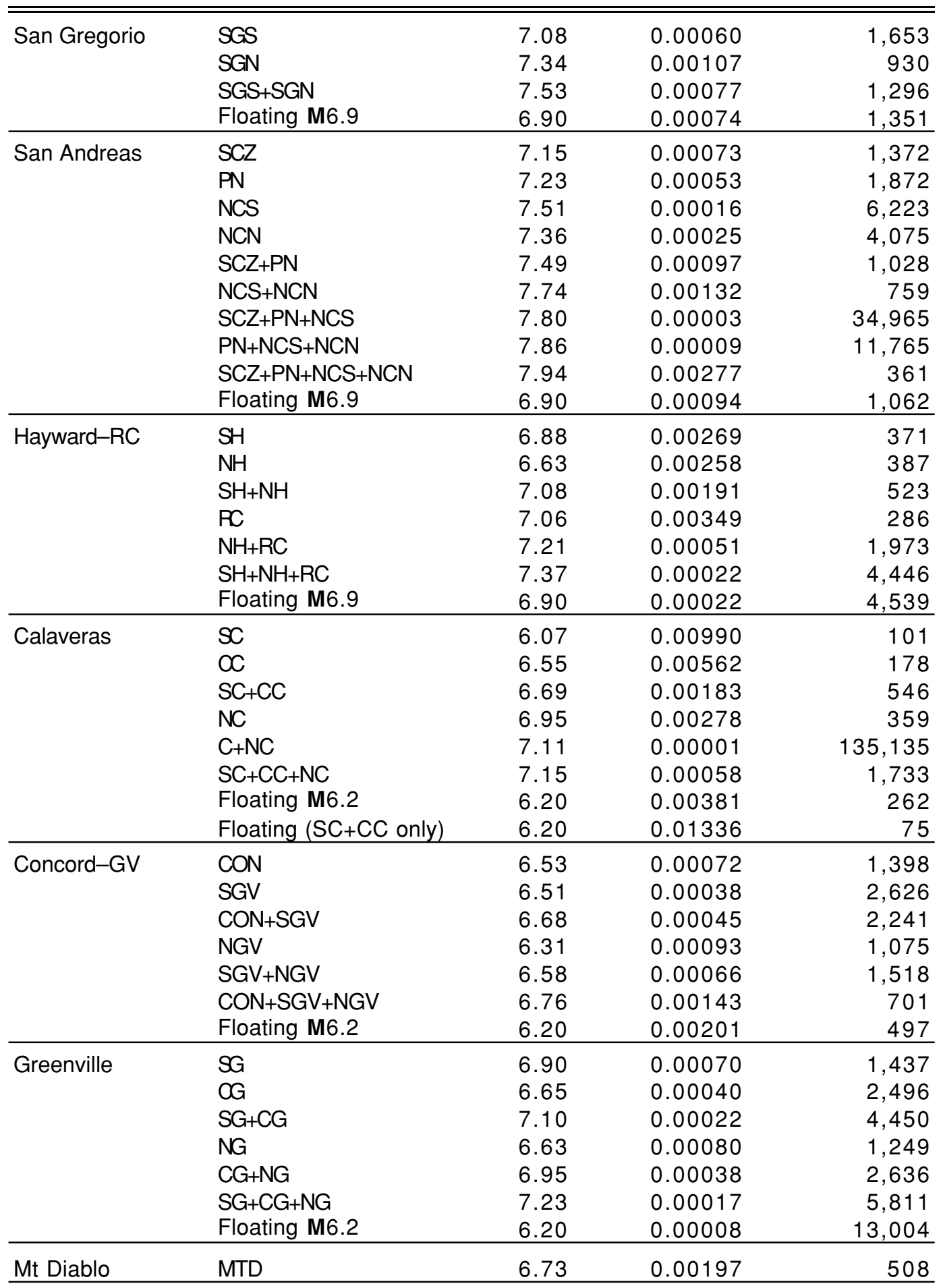


Catalog Data and time Interval
Estimated Annual Rate

Of Earthquakes

$\mathrm{M} \geq 6.7$

$M \geq 7$

$6 \leq \mathrm{M} \leq 6.7$

\section{Bakun, 1999}

$\begin{array}{llll}1850-1905 & 0.060 & 0.032 & 0.195 \\ 1850-1877 & 0.040 & 0.021 & 0.13 \\ 1878-1905 & 0.080 & 0.043 & 0.26\end{array}$

\section{HERP + CNSS}

\section{Declustered Catalog}

$\begin{array}{llll}1942-1949 & 0.015 & 0.0083 & 0.044 \\ 1950-1959 & 0.013 & 0.0073 & 0.039 \\ 1960-1969 & 0.011 & 0.0059 & 0.031 \\ 1970-1979 & 0.013 & 0.007 & 0.037 \\ 1980-1989 & 0.017 & 0.0093 & 0.049 \\ 1990-1998 & 0.016 & 0.0087 & 0.046\end{array}$


Table 5. Rate of rupture in segments in $M \geq 6.7$ Earthquakes [See table 2 for explanation of segment codes]

\begin{tabular}{|c|c|c|}
\hline Fault system & Segment & $\begin{array}{c}\text { Mean rate } \\
(1 / y r)\end{array}$ \\
\hline
\end{tabular}

San Gregorio

SGS $\quad 0.00163$

615

SGN

0.00228

438

San Andreas

SCZ

0.00461

217

$\mathrm{PN}$

0.00455

220

NCS

0.00472

212

NCN

0.00467

214

Hayward-RC

$\mathrm{SH}$

0.00423

236

$\mathrm{NH}$

0.00339

295

$\mathrm{RC}$

0.00424

236

Calaveras

$\mathrm{SC}$

0.00142

703

$\infty$

0.00268

374

NC

0.00309

324

Concord-GV

CON

0.00101

991

SGV

0.00114

881

NGV

0.00094

1,060

Greenville

$S G$

0.00095

1,057

$O G$

0.00083

1,206

NG

0.00074

1,359

Mt Diablo

MTD

0.00092

1,089 
Table 6. Clock advance due to stress transfer from 1906 earthquake

[Note: A positive (negative) clock advance corresponds to an increase (decrease) in fault driving stress, moving the fault closer to (farther from) failure. See table 2 for explanation of segment codes.]

Fault segment

\section{6 clock advance (yr)}

\section{Segment name}

San Gregorio North

San Gregorio South

Rodgers Creek

Northern Hayward

Southern Hayward

Northern Calaveras

Central Calaveras

Southern Calaveras

Northern Green Valley

Southern Green Valley

Concord

Northern Greenville

Central Greenville

Southern Greenville

Mount Diablo thrust
Code simplest

SGN

SGS

$\mathrm{RC} \quad-27.9$

$\mathrm{NH}$

$-31.1$

$\mathrm{SH}$

NC

$\infty$

SC

NGV

SGV

$\mathrm{CON}$

$-20.1$

$-14.6$

$-13.8$

-84.7
-83.9
-67.5

$-4.8$

max

$\min$

2.1

42.4

$-7.1$

$-74.0$

$-75.2$

$-17.0$

$-3.9$

$-3.4$

-84.7
-83.9
-67.5

$-92.1$

$-115.6$

0.4

$-8.7$

$-13.1$

$-134.5$

$-2.5$

$-10.1$

$-86.1$

$-200.7$

$-8.0$

NG

$-23.1$

$-24.3$

$-135.7$

$-6.9$

$\circlearrowleft \mathrm{G}$

SG

$-15.8$

$-106.8$

$-7.6$

MTD $\quad-1.3$

23.0 


\begin{tabular}{|c|c|c|c|c|c|}
\hline \multirow[b]{3}{*}{ Fault segment } & \multicolumn{4}{|c|}{ Probability model } & \multirow[b]{3}{*}{$\begin{array}{c}\text { Experts' } \\
\text { weighted } \\
\text { aggregate }\end{array}$} \\
\hline & \multirow[b]{2}{*}{$\begin{array}{l}\text { Expon- } \\
\text { ential }\end{array}$} & Brownic & $\begin{array}{l}\text { Passage } \\
\text { ne }\end{array}$ & \multirow[b]{2}{*}{$\begin{array}{l}\text { Time Pre- } \\
\text { dictable }\end{array}$} & \\
\hline & & $\begin{array}{c}\text { Without } \\
\text { Inter- } \\
\text { actions }\end{array}$ & $\begin{array}{l}\text { With Inter- } \\
\text { actions }\end{array}$ & & \\
\hline
\end{tabular}

San Gregorio Fault

SGS - San Gregorio South

0.05

0.07

0.06

0.06

SGN - San Gregorio North

0.07

0.12

0.07

0.08

San Andreas Fault

SCZ - Santa Cruz

0.13

0.12

0.09

0.07

0.10

PN - Peninsula

0.13

0.12

0.11

0.21

0.15

NCS - North Coast South

0.13

0.13

0.12

0.11

0.12

NCN - North Coast North

0.13

0.13

0.12

0.05

0.10

Hayward/Rodgers Creek fault system

$\mathrm{SH}$ - Southern Hayward

0.12

0.17

0.12

0.25

0.17

$\mathrm{NH}$ - Northern Hayward

0.10

0.20

0.17

0.16

RC - Rodgers Creek

0.12

0.23

0.22

0.20

Calaveras Fault

SC - Southern Calaveras

0.04

0.09

0.08

0.07

CC - Central Calaveras

0.08

0.21

0.16

0.15

NC - Northern Calaveras

0.09

0.23

0.21

0.18

Concord/Green Valley fault system

CON - Concord

0.03

0.07

0.06

0.06

SGV - Southern Green Valley

0.03

0.08

0.07

0.07

NGV - Northern Green Valley

0.03

0.07

0.06

0.06

Greenville Fault

\begin{tabular}{llllll} 
SG - Southern Greenville & 0.03 & 0.04 & 0.04 & - & $\mathbf{0 . 0 3}$ \\
CG - Central Greenville & 0.02 & 0.03 & 0.03 & - & $\mathbf{0 . 0 3}$ \\
NG - Northern Greenville & 0.02 & 0.03 & 0.03 & - & $\mathbf{0 . 0 3}$ \\
\hline
\end{tabular}

Mount Diablo blind thrust

MTD - Mount Diablo

0.03

0.04

0.04

0.04 
Table 8. Probability of at least one $M \geq 6.7$ earthquake before 2030, by fault and in $S F$

\begin{tabular}{|c|c|c|c|c|c|}
\hline \multirow{3}{*}{ Fault System } & \multicolumn{4}{|c|}{ Probability model } & \multirow{3}{*}{$\begin{array}{c}\text { Experts' } \\
\text { weighted } \\
\text { aggregate }\end{array}$} \\
\hline & \multirow{2}{*}{$\begin{array}{l}\text { Expon- } \\
\text { ential }\end{array}$} & \multicolumn{2}{|c|}{$\begin{array}{c}\text { Brownian Passage } \\
\text { Time }\end{array}$} & \multirow{2}{*}{$\begin{array}{c}\text { Time Pre- } \\
\text { dictable }\end{array}$} & \\
\hline & & $\begin{array}{c}\text { Without } \\
\text { Inter-actions }\end{array}$ & $\begin{array}{l}\text { With Inter. } \\
\text { actions }\end{array}$ & & \\
\hline San Gregorio & 0.08 & 0.13 & 0.09 & - & 0.10 \\
\hline San Andreas & 0.18 & 0.17 & 0.14 & 0.30 & 0.21 \\
\hline Hayward-Rodgers Creek & 0.25 & 0.37 & 0.32 & - & 0.32 \\
\hline Calaveras & 0.11 & 0.23 & 0.21 & - & 0.18 \\
\hline Concord-Green Valley & 0.04 & 0.07 & 0.06 & - & 0.06 \\
\hline Greenville & 0.06 & 0.06 & 0.06 & - & 0.06 \\
\hline Mt Diablo & 0.03 & 0.04 & 0.04 & - & 0.04 \\
\hline Background & 0.09 & 0.09 & 0.09 & - & 0.09 \\
\hline $\begin{array}{l}\text { Regional aggregate } \\
\text { (includes background) }\end{array}$ & 0.60 & 0.73 & 0.68 & - & 0.70 \\
\hline
\end{tabular}


Table C1. Source Parameters for Large California Strike-slip Earthquakes

\begin{tabular}{|c|c|c|c|c|c|c|}
\hline Date & M & $\mathbf{M}_{0}{ }^{1}$ & $\begin{array}{l}A \\
\left(\mathrm{~km}^{2}\right)\end{array}$ & $\begin{array}{l}\mathrm{W} \\
(\mathrm{km})\end{array}$ & $\begin{array}{l}\mathrm{L} \\
(\mathrm{km})\end{array}$ & Source \\
\hline \multirow[t]{4}{*}{1857} & 7.85 & 670 & 3564 & 12 & 297 & Wells and Coppersmith (1994) \\
\hline & 7.76 & 488 & 3000 & 10 & 300 & after Sieh (1978) \\
\hline & 7.83 & 634 & 3900 & 13 & 300 & after Sieh (1978) \\
\hline & 7.89 & 780 & 4800 & 16 & 300 & after Sieh (1978) \\
\hline \multirow[t]{3}{*}{1868} & 6.76 & 15.6 & 576 & 12 & 48 & Wells and Coppersmith (1994) \\
\hline & 6.95 & 30 & 520 & 10 & 52 & Yu and Segall (1996) \\
\hline & 7.04 & 41 & 780 & 15 & 52 & Yu and Segall (1996) \\
\hline \multirow[t]{3}{*}{1872} & 7.61 & 292 & 1620 & 15 & 108 & Wells and Coppersmith (1994) \\
\hline & 7.6 & 300 & 1100 & 15 & 110 & Beanland and Clark (1994) \\
\hline & 7.46 & 175 & 1396 & 12.5 & 110 & Stein and Hanks (1998) \\
\hline \multirow[t]{2}{*}{1906} & 7.9 & 790 & 5184 & 12 & 432 & Wells and Coppersmith (1994) \\
\hline & 7.88 & 750 & 4700 & 10 & 470 & Thatcher et al. (1997) \\
\hline \multirow[t]{2}{*}{1940} & 6.92 & 27 & 660 & 11 & 60 & Wells and Coppersmith (1994) \\
\hline & 6.97 & 32 & 585 & 9 & 65 & King and Thatcher (1998) \\
\hline \multirow[t]{4}{*}{1989} & 6.92 & 267 & 640 & 16 & 40 & Wells and Coppersmith (1994) \\
\hline & 6.95 & 30 & 720 & 18 & 40 & Somerville et al. (1999) \\
\hline & 6.95 & 30 & 481 & 13 & 37 & Lisowski et al. (1990) \\
\hline & 6.95 & 30 & 360 & 10 & 36 & Arnadottir et al. (1992) \\
\hline \multirow[t]{4}{*}{1992} & 7.34 & 114 & 744 & 12 & 62 & Wells and Coppersmith (1994) \\
\hline & 7.22 & 75 & 1035 & 15 & 69 & Somerville et al. (1999) \\
\hline & 7.31 & 103 & 650 & 10 & 65 & Hudnut et al. (1994) \\
\hline & 7.27 & 90 & 650 & 10 & 65 & Freymueller et al. (1994) \\
\hline
\end{tabular}

${ }^{1}\left(10^{25}\right.$ dyne-cm) 